\title{
Ethics Related to Mental IIInesses and Addictions
}

\author{
Barbara J. Russell \\ Centre for Addiction and Mental Health \\ and University of Toronto's Joint Centre for Bioethics \\ Canada
}

\section{Introduction}

\subsection{Overview}

The general public learns about mental illnesses and addictions primarily from mainstream media, including news reports, television programs, and movies. The stories presented usually centre on sensationalism or danger such as those about young women at lifethreatening stages of anorexia nervosa or people labelled as "psychopaths." Or the stories appeal to our feelings of sympathy or empathy such as those about people with untreated mental illnesses sleeping on subway vents during winter or a person with moderate dementia who finds greater companionship with someone other than their spouse. These reports and programs often oversimplify the ethical nature of these situations by dramatically pitting one value against another: self-determination versus life, public safety versus rehabilitation, quality of life versus non-abandonment, and happiness versus loyalty. Distilling situations down to one or two values can be motivated more by the ongoing competition for the public's attention and/or economics than by the demands of concise reporting.

However, mental illnesses and addictions are complex, as those who live with a mental health or addiction problem and their families can attest. The high incidence of mental health and addiction problems and their disruptive and lasting impact on people's lives, families' sustainability, communities' well-being, and employers' productivity are publicly acknowledged more often now. In recent years, more and more governments (civic, provincial/state, national) and employers have become interested in listening to those with first-hand experience of these conditions and to those who have developed holistic, integrative ways to diagnose and offer treatments and supports earlier and longer.

Ethical complexity is not limited to crises and strong emotions. It exists in everyday, seemingly routine questions, experiences, and situations. The cases in section 1.2, below, help illustrate the wide diversity of ethically complex, "real world" situations that those living with a mental health or addiction problem, their families and friends, professional healthcare workers and their managers commonly face. Accordingly, the selected cases involve a variety of participants, interests, contexts, histories, health problems, options, and values. The healthcare ethics literature---which is quite extensive now---and educational workshops and courses encourage their readers and participants to increase their understanding of a particular situation or question and they offer various theories, concepts, 
and approaches to help make ethically defensible decisions. This chapter has similar objectives: first, to broaden and deepen readers' understanding of ethically relevant aspects in living with a mental health or addiction concern; second to increase the understanding of ethically relevant aspects in offering, managing, and accessing healthcare services; and third, to increase readers' abilities to determine which options or responses to a particular issue or situation are and are not ethically sound.

With this said, though, it is not just "soundness" or basic justification that will be emphasized here. Too often decisions can be merely adequate ethically or minimally ethical. The appropriate goal is strongly ethical decisions and responses. Whether treating spina bifida, colitis or alcohol dependence, clinicians and healthcare organizations do not talk about providing merely adequate or merely acceptable therapies. In terms of the "technical" aspects of the programs and treatments they offer, their language is peppered with adjectives such as high quality, incomparable, excellent, leading, the best, and world-class. Why then settle for ethically "okay" or ethically adequate analyses and conclusions about these same interventions? A healthcare treatment or service cannot be described as first-rate or promulgated as "the standard of care" if its related ethical features have been simplified or minimized. The level of attention to and engagement with an intervention or service's ethical features directly and proportionately impacts its quality.

Two other considerations contribute to ethically strong health care practices and services. Health and healthcare are not about decisions and choices only. They are also and inescapably about human interactions, whether it is the person's interactions with her family, teachers, or employer, or her interactions with her healthcare team, or the interactions among her interprofessional and interagency workers. In his book, Ethics and the Clinical Encounter (2004) and as a philosopher who spends a lot of time in hospitals, Richard Zaner insightfully explores and questions the formal-informal and multivalent-ambiguous interactions that occur routinely between patients and professionals. "How" we are with one another matters a great deal ethically. Arthur Frank, a well-known sociologist whose scholarly interests include the meaning of illness and interactions with professionals and institutions, suggests, "We should speak less of ethics as some activity or substantive content that appears to stand alone and more of ethical relations" $(2004,357)$. In the case of Omar, below, if the defensible option is transferring him to an outpatient program, how this is explained remains important ethically. If the explanation about the pending discharge from hospital and transfer to a community program is condescending, dismissive, and implies the decision is non-negotiable, Omar's defensiveness, anger, and non-cooperation should surprise no one. Unethical language, tone, and demeanour can transform what seems, at the time, to be a good option---all things considered---into a poor and unpersuasive option.

Frank cautions against excessive emphasis on decision making when he states that:

"Being ethical... has less to do with making a single decision than with initiating a process---often a very slow process---of a person or persons coming to feel that how they acted was as good as it could have been, given the inherent impossibility of the situation (Ibid, 355-6).

Although "inherent impossibility" is meant to refer to healthcare situations typified by complicated machinery, invasive procedures, and life-threatening events (e.g., in intensive care units, in operating rooms, and in emergency departments), Frank's point holds true for long-term mental illnesses and substance use problems, too. Accordingly, this chapter's second noteworthy consideration is participants' characters or who they are, from both the 
perspectives of important people in their lives and from their own perspective. In modern bioethics discussions and analyses, virtue ethics as an ethical theory has tended to rely on Aristotle's Nicomachean Ethics (350 B.C.) and contemporary philosopher Alasdair MacIntyre's After Virtue (first published in 1981). More recently, philosopher Lisa Tessman has insightfully examined the durability and praiseworthiness of character virtues in progressively oppressive and harsh situations and societies. Burdened Virtues: virtue ethics for liberatory struggles (2005) is a welcome rehabilitation of virtue theory such that it is highly relevant for mental health and addictions settings because unfortunately these settings can be restricting, stigmatizing, and marginalizing.

The remainder of this chapter starts with a description of seven cases and then describes ethically salient concepts and values for mental illnesses and addictions' questions, issues, and situations. Admittedly, some of these concepts are meaningful for any illness, injury or health condition. Nonetheless, certain ethical concepts are especially meaningful for serious mental health and addiction problems. Concluding this chapter by identifying and applying ethical values relevant to each of the opening seven cases might be the expected ending. The experiences of a newly-minted ethicist explain why the actual conclusion is somewhat different.

Daniel Sokol (2007) wrote a perceptive editorial piece in the BMJ describing his first days and weeks as an ethicist in a large general hospital in London. Surrounded by innumerable procedures, treatments, and appointments as he accompanies a nephrologist, Sokol observes that, "My proximity to the patients, instead of highlighting the ethical commitments, obscured them" (670). It took awhile before he could see beyond what was urgent and close. With time, he began to see the underlying ethical quandaries, unasked questions, and troubling assumptions. His personal experience underscores an ability or skill that is critical for strong ethical analyses and responses: awareness or discernment (Holland, 1998; Nussbaum, 1985).

In this light, the section on ethical concepts and values is followed by four sections describing other considerations that bear significantly on what constitutes a strong ethically defensible decision or response for mental health and addictions issues and questions. These four sections cover clinical, legal, organizational and systemic factors that cannot be ignored or dismissed by those endeavouring to understand and respond well ethically. In healthcare, ethics does not stand alone.... an unfortunate notion that can be reinforced when ethics specialists dramatically "parachute in" to meet briefly with a clinical team and the patient/family and leave just as quickly. Moreover integrating all five aspects means that ethics never trumps everything else (Russell, 2008). It is both naïve and impractical for an ethicist to say, "Just do what is most ethical to do in this situation." Therefore this chapter's concluding section re-visits the opening cases and identifies their ethical, clinical, legal, organizational, and systemic considerations and analyzes what qualifies as strongly ethical decisions and, as per Frank's wisdom, ethically strong interactions and characters.

Stylistic note: Many people consider the term "mental illness" to include addictions. In this chapter, however, they routinely will be referred to separately to ensure that addiction problems are not overlooked. Instead of "substance dependence, misuse, and abuse," the word "addiction" is used to help reduce this chapter's length. Ethical worries about the word will be discussed in section 6.1. Recently, however, various professionals have recommended "addiction" be used in the future $D S M-V$, the diagnostic manual of North American psychiatry. Different words are used to refer to those living with a mental health 
or addiction problem, such as patient, client, consumer, and survivor. "Client" will be used most often in this chapter because it portrays a reasonable balance in the power and interests between the individual and healthcare professionals and organizations and because most people with these health problems access treatments while living in the community.

\subsection{Prototypical cases}

The following cases illustrate the ethical complexity of everyday practices and interactions in mental health and addiction settings. It is accidental and unintentional if any case is identical to a real event or person. The cases, however, have been written to be representative amalgams of common situations and issues. All names are hypothetical and used for easier reading and to underscore the human and personal dimensions.

Case 1: Noticing that "Sergei" looks flushed, talks rather loudly and directly, and his breath smells mint-y sweet, the community health clinic nurse asks him whether he has had a few drinks this morning. He chuckles, shifts nervously on the examining table, and says, "Well, not really." "Nothing?" she responds. He looks down at the floor and says "No." This is Sergei's fourth visit for recurring back and leg pain and stiffness. Test results and recommendations from a hospital-based specialist have just arrived. She proceeds to test and document his reflexes, blood pressure, pulmonary-stomach-bowel sounds, heart rate, and temperature.

As she walks down the corridor to see the next patient, the nurse suddenly wonders whether Sergei, who is 46 years old and immigrated with his wife and 2 children from Russia five years ago, drove to the clinic "under the influence" and whether he drinks and drives regularly. She vaguely recalls that he presented the same way at a previous appointment. There is provincial legislation that requires physicians to notify the Transportation Ministry if they believe a patient has a medical condition that makes his or her driving dangerous. The nurse asks herself, "The doctor who will talk with Sergei about the specialist's report... should I tell her about what I am thinking or will she make her own decision when she sees him?"

Case 2: About 2 weeks ago, "Ana $\mathrm{Li}^{\prime}$ was admitted to the mental health unit from the emergency department (ED). Ana Li's mother brought her to the ED because Ana Li was experiencing hallucinations, not thinking clearly, and becoming more and more upset and frenetic. Since admission, Ana Li has resumed taking previously prescribed medications for bipolar disease (she is 19 years old and was assessed as having the capacity to legally consent to treatment). Although she has attended a few of the unit's weekly group activities, sustained or in-depth discussions with her are not yet possible so psychotherapeutic options have not been offered thus far.

During this morning's team review of all their clients, one member mentions Ana Li's continuing hypersexual statements and wishes, and asks whether anyone else worries she will act on them. He suggests her status should be changed from "voluntary" to "involuntary" for awhile and she be restricted to the unit because she may trade sexual "favours" in return for cigarettes from co-clients or someone she meets on or near the hospital grounds. Another team member shakes her head and says, "The Mental Health Act is more interested in preventing major harms like suicide or assault, not casual sex." Another team member immediately adds, "But we have to be realistic about this. Hasn't each one of us remarked how 'drop dead gorgeous' Ana Li is? Plus if there's unprotected 
sex, then we are going to be dealing with a sexually transmitted disease or even a pregnancy."

Case 3: One of the organization's clinical directors has been working there for almost three months. By introducing new initiatives, he has two goals for today's monthly meeting with the clinical managers and professional heads: (1) to move the program more quickly to the forefront of contemporary mental health and addictions practices, and (2) to be a role model for continuous innovation. One initiative will require at least one home visit for all new referrals in order to understand more quickly and thoroughly clients' individual lived experiences, available supports, and enduring barriers to recovery. The second initiative involves hiring a peer support worker to be a member of each clinical team. Peer support workers serve as unique resources and supports to clients because they have personal knowledge both of living with a mental health or addiction condition and of some of the different ways that family and friends, the healthcare system, the legal system, and social service organizations may and may not contribute to recovery. The director is unsure whether his plans will be met by eagerness, defensiveness, or stony silence.

Case 4: A judge rules that "Jane," who is 68 years old, should not be jailed as punishment for assaulting her landlord when he said she would be evicted in seven days if her apartment remained a fire hazard and malodorous. The landlord fell trying to dodge Jane's fists and a resulting cut required an emergency department visit and six sutures. The judge's ruling diverts Jane to a psychiatric facility for treatment of a mental health condition that results in extreme hoarding behaviour. Review Board hearings are scheduled after the first six months of hospitalization and then every twelve months. Jane is not swayed by her Legal Aid lawyer's advice that she not testify at the first hearing because her nervousness and anger may persuade the Board to not change the order. She testifies and is very nervous, quite disorganized in her responses, and uses some clearly racist language. The Board does not change the mandatory hospitalization order. The next hearing is in one month. Her clinical team believes Jane has improved from her participation in eleven months of behaviour therapy, trauma counselling, and medications, such that they will recommend conditional discharge into the community. Yet a few team members worry that her lawyer will let her testify and her nervousness and inflammatory comments will again persuade the Board to continue the hospitalization order.

Case 5: "Omar" has lived with moderately severe schizophrenia for 30 years; he's now 52 years old. He has lived in different group homes and subsidized housing, has not been close with most of his family since young adulthood, and relies financially on a modest governmental disability program. Omar has inconsistently taken and sometimes discontinued taking various typical and atypical antipsychotic medications for different reasons: the bothersome and discouraging side effects, not wanting to depend on drugs, and simple forgetfulness. Emergency hospitalizations have been required from time to time in order to re-commence or revise medications to reduce distressing thoughts and hallucinations as well as to re-connect him with the community mental health agencies in and near his town. Omar's general health is poor: pulmonary and cardiovascular problems due to chronic smoking and, as a likely result of long-term antipsychotic medications, diabetes, which has been poorly controlled.

Police officers bring him to the psychiatric emergency after finding him asleep in a cold alley on a night when the temperature dips nears freezing. He is hospitalized to resume his 
psychotropic medications and to try to find a housing facility that offers a modest level of supervision. Since hospitalization, Omar's leg and foot ulcers unfortunately have increased in size and depth despite antibiotic administration. Efforts to keep the ulcers clean and bandages on and clean typically have resulted in arguments between nursing staff and him. The standard of care for the diabetic ulcers now requires debriding and deep cleaning, which will need to done at a nearby tertiary hospital by a specialist. Two weeks ago, Omar agreed to the proposed debridement. On the morning of the appointment, however, he tells the staff member who will accompany him to the hospital, "There is no way I am going to any hospital." Over the next few days, his assigned nurses explain the benefits of the specialist visit and debridement. He eventually agrees again to go because "I don't want to lose my foot." The visit is scheduled for the following week. A week passes. Today when a staff member says "Omar, it's time for us to head over to see the specialist about the sores on your foot and leg," he replies, "No thanks. I don't want someone digging around my foot and leg. I'm staying here."

Case 6: The concurrent disorders (comorbid addiction and mental illness) program is organizing a special day-long workshop to increase community-based physicians', therapists', and addictions workers' knowledge and support for families with a member who has gambling or prescription opioid problems. Four smaller community-based services were invited to help organize the workshop as a way to increase collaboration among the organizations. To attract more physicians, therapists, and addictions workers, two prominent speakers have been invited and the venue will be at one of the area's nicer hotels. Representatives from each partner organization are discussing ways to cover the costs of the hotel's food and beverage services, room rental, and the speakers' travel expenses. Setting the registration fees high enough to cover the costs will likely discourage too many workers at smaller agencies or programs from attending. One of the representatives suggests contacting the regional pharmaceutical representative and a local brewery representative to make a financial donation. Another representative suggests having a raffle for a "fancy spa weekend" as a way to increase the number of registrants.

Case 7: "Sandra" and her partner permit her older brother "Edward" to move into their home while he looks for somewhere affordable to live near his new job. Since she uses many of the household practices they grew up with, Sandra knows her home is a place of comfort and love for him. He promises to see his therapist every three weeks and to have a community physician renew his psychiatric medication before there are only ten pills left. It is important to hear him explicitly commit to seeing the therapist and taking the medications because in the past, he has become so ill that he often verbally abused and threatened those with whom he lived, such as a favourite uncle and his family.

Five months later, Sandra contacts the physician---whose name she finds on the prescription bottle---to ask if crushing the pills into Edward's food decreases their efficacy. She had started doing this two months ago when she learned that Edward had stopped taking the pills because he believed he no longer needed them and subsequently became angry when she reminded him of his earlier promise. Since then, whenever Sandra has found a new prescription slip for the psychiatric medications in Edward's room, she has had it filled by the neighbourhood pharmacist. Yet whenever the physician asks Edward at their appointments whether he is taking the psychiatric medications and feels they are helping, Edwards always says he is taking them as prescribed and they seem to help. The physician refrains from telling him about the conversations with his sister and her actions because he 
believes that the medications, residing in a home environment, and the sister's involvement are in Edward's best interests.

\section{Foundational ethical considerations}

A familiar claim by those working as ethics specialists in hospitals and those teaching healthcare ethics is "It's ethics all the way down." Ethics involves what should matter or what should be valued and based on such values, what should be our aspirations, behaviours, and relationships. The word "should" is important here; in philosophical settings, "should" represents the normative element of ethics. There is a critical difference between what is valued and what should be valued. We must ask what are the reasons to value something and whether they are defensible or justified reasons. It is important to underscore that not all values are ethical, though everything that is ethical is based on values. This distinction is often disregarded in healthcare ethics.

Healthcare is informed by a host of values, including self-interest, economics (which can include efficiency and productivity measures), reputation, relationships, and politics (i.e., power). For example, a decision to generate added revenue by charging to train community workers can be justified by economics. To justify it ethically, though, the added revenue would have to be used, for instance, to provide more recreational activities for clients' enjoyment and rehabilitation. If the additional monies were used to increase the agency's profile as the area's "go to" agency, then its justification would be focused on politics and/or reputation. Further examination would be required to determine if a better reputation will or will not contribute to achieving the agency's ethically defensible goals.

\subsection{Being humane}

It seems obvious that illnesses do not detract from being a human. Yet being a human, that is a member of the homo sapiens species, is not the same as being humane. "Being humane" typically means thinking, behaving, and interacting in certain ways. In the context of mental health and addictions programs and services, being humane warrants discussion because it may be what is first sacrificed when units are busy and staff levels are low.

Much has been written in the ethics literature and the nursing literature about the importance of caring and compassion: 21,246 articles and 1,285 articles respectively are listed when these key words are used with CINAHL, a primary nursing database. It is important, however, to distinguish between caring/compassion and respect because they are made manifest by different actions. If a close friend of someone unable to leave his home due to a relapse of his depression arranges an outing that will be as "easy" as possible to accept, this is an act of caring. Prior to deciding whether to go, if the depressed person listens carefully to what has been arranged and why specific arrangements have been made, this is an act of respect. If a case worker has a few toys in his office to occupy clients' children and does not keep clients waiting more than five minutes beyond their appointment time, he has been, respectively, caring and respectful. As Frank incisively points out, "Being ethical... is never anything that one has" $(2004,356)$. It is something one does or strives to do. Skilfulness is relevant to ethics, just as it is to nursing and case management, in terms of astutely discerning what is required and how it can best be accomplished. Ineptness should not be repeatedly forgiven simply because the person had good intentions. 
Being humane should also include generosity and welcome, two qualities often overlooked in everyday interactions. Generosity is not about money. Instead it is a philanthropy of spirit and hope wherein people are pro-the Other. Yet this generosity does not equate to strident self-sacrifice and Puritanism. It involves giving but it can be in small, subtle ways. While generosity is a giving or contributing to, without expectation of return, welcome is a taking in wherein the presence of the Other is appreciated. The history of mental health and addictions work and settings includes far too little generosity and welcome. This constitutes an ongoing challenge for contexts in which police powers can be employed: how to once again be seen as generous and welcoming after a client has lost some basic civic rights and freedoms (e.g., involuntary hospitalization, use of a seclusion room)? Welcome and generosity can fade in the wake of efficiency measures, bed flow pressures, staff shortages, and management by statistics; operations may improve economically, but not ethically.

Finally, being humane means relationships are inescapably important, given that human beings are social creatures. In health care settings, ongoing attention must be paid to honouring and maintaining appropriate boundaries between clients and staff. This can be especially challenging because workers utilize various methods to examine and influence highly personal and intimate aspects of clients' behaviours. Moreover clients may not have many affirming and reliable relationships, often due to their illnesses' symptoms, which, in turn, cause family and friends to disengage. Healthcare workers may believe compassion justifies them filling this relational void by taking on the role of friend, family, or confidante. This erroneous belief increases the likelihood of enduring boundary crossings or repeated boundary violations. It is not surprising that medical and nursing books and curricula routinely discuss maintaining appropriate professional relationships and avoiding inappropriate personal relationships, boundary crossings and boundary violations.

Being humane can be most challenging when staff work with individuals who are diagnosed as having a personality disorder. While the resulting behaviours seriously test the therapeutic alliance, too often the label of "difficult client" or "difficult patient" predetermines all activities and it becomes a self-fulfilling prophesy (Hilfiker, 1992; Knesper, 2007; Lauro et al., 2003). In the case of those diagnosed with sociopathy, public rhetoric has often labelled these people as "criminally insane." Since they appear not to be motivated by common morality, these individuals may be judged to be less than human. When working with clients with personality disorders, healthcare workers must avoid such moral judgments. Healthcare and health professions' mandate is to help preserve and restore health and well-being and alleviate suffering, irrespective of inferences about a person's goodness or badness (Pouncey \& Lukens, 2010). With this said, though, employers must provide effective forums and measures to alleviate a worker's fear of a specific client and to prevent or address dislike of or negative feelings towards certain clients (e.g., someone convicted on infanticide). The concept of countertransference is well-known in the psychiatric and psychological fields. It is a professional's response to a client's behaviours or statements such that the professional shifts into an inappropriate role (e.g., parent, disciplinarian, rescuer). Psychiatry and psychology textbooks and courses teach ways to prepare for, recognize and effectively address countertransference. Similar attention to the psychological responses of other allied health workers is needed because their negative (or sometimes unchecked positive) feelings and attitudes can obstruct clients' recovery. 


\subsection{Being a person}

Personhood or being a person is a longstanding concept in academic communities, regardless of whether it is political science, sociology, theology or moral theory. Much debate has been generated because of its political, legal and ethical significance: those who legitimately qualify as "persons" must be accorded a certain level of attention, respect, and assistance while "non-persons" can be accorded less. Various philosophers have developed different definitions of personhood. For instance, British philosopher John Locke held that a person was a being with a complex, psychological conscious that continued over time. Focusing on consciousness, cognition, and affect meant that as time passed, people with progressive dementia would become different people compared to their former selves and when certain defining abilities faded, non-persons. Alternative definitions have been offered; for example Rosfort and Stanghellini hold that personhood is "the identity of an embodied self, which is embedded in a coexistence with other selves through time" (2009, 286). Grant Gillett (2002) appeals to a cumulative and evolving narrative of "my life" while Bruce Jennings (2009) posits the "memorial person" wherein someone with advanced dementia remains a person and connected with her earlier years through the memories of those around her.

Farah and Heberlin (2007) present various theorists' definitions of personhood to demonstrate that consensus in defining such a potent concept still does not exist yet. In fact, Tom Beauchamp (1999) recommends discontinuing efforts to refine the moral or metaphysical attributes of personhood. He favours working on concepts that more directly capture the lived reality of daily life. In the case of mental illnesses, clinician, family, employers, and the general public's interest can be focused on psychiatric diagnoses, impairing symptoms and behaviours so much that individuals are de-personalized. Hospital and governmental agencies' operational and administrative practices can depersonalize, too.

De-personalization is ethically indefensible because the individual is not recognized as unique (Peterneliji-Taylor, 2004; Sierra et al., 2006). Instead forms and computer programs can average or homogenize clients such that they become "another case of $X^{\prime \prime}$ or as Flanagan et al. note, "the medical chart." De-personalization silences such that the individual's unique perspective, lived history, and hard-won expertise are not sought or are ignored. Moreover "othering occurs in relationships between the powerful and the powerless, where vulnerabilities are exploited and where domination and subordination prevail" (PeternelijiTaylor, 133). French philosopher Emmanuel Levinas' work counters de-personalization by morally and positively privileging the Other and his presence-to-me (Burns, 2008; Nortvedt, 2003; Standish, 2001). Simply put, if I am in the presence of someone else, I am automatically and inarguably obliged to respond to him and respond in certain ways.

Respect is one of the most popular concepts employed to avoid de-personalization in mental health and addictions settings. Too often, however, determining what actually demonstrates respect in a particular situation with a particular person or group of people receives scant attention. Instead a kind of basic civility is considered sufficient. But it is not, especially when healthcare institutions and clinicians are expected to provide high quality treatment and care. Preventing de-personalization of individuals with mental health and addictions problems requires Levinas-ian active engagement with them and equal acceptance plus a kind of existential attention and presence. Processes for information disclosure, clinicians' truth telling, and obtaining informed consent can dominate routine interactions with clients and their families such that little consideration is given to clinicians and staff being with 
clients and families. The effect is eroded personalization of clinicians and staff as well as of clients and families. In other words, healthcare workers also become interchangeable, "all the same," and regrettably for those they serve, forgettable.

\subsection{Being a member of a community}

In mental health and addictions, considerable focus is paid to people's rights and freedoms. This makes sense because it is so common for others to intervene to limit individual freedoms and obstruct the exercise of rights. Ethics related justification for such interference typically comes from safety concerns, either for the individual herself or for others. However a hidden, but common, concern is the existence of double standards wherein those with suspected or diagnosed mental health problems are not permitted to do certain things while the rest of society are. Some examples help make this point. Restrictions on sexual and intimate activities between hospitalized clients are often excessive. The only permitted activities are those deemed socially responsible, such as not engaging in "casual sex" or "risking a pregnancy." And yet a common freedom is for people to decide how sexually active they will and will not be. Moreover women are permitted in many countries to seek an abortion, especially before the third trimester, so it is discriminatory to summarily hold that women with mental health concerns must always act so that pregnancy avoided. A more ordinary example of double standards involves medication regimens. Exercising, eating balanced meals, getting sufficient sleep, and drinking enough water contribute to feeling and performing well. Most people do not engage in such activities consistently. In general, people are non-compliant. Yet those who have mental health problems are expected to be highly compliant with their medications and non-compliance is summarily often assumed to reflect abnormally impaired thinking abilities and motivations.

The notion of citizenship moves people with mental illnesses "beyond the mere allocation or management of financial or physical resources and implies instead a form of moral assistance that calls for their full participation" (Perron et al. 2010; 108). Rights and freedoms associated with citizenship are ethically very important. But what is often disregarded is whether a person belongs within general society and within different sub-groups that are meaningful to him. Belonging here emphasizes that the person is a valued and equal member such that if he is absent, he is missed and he owes other members certain things just as they owe him. He is accepted "as is," both in terms of recognizing inescapable human fallibility, inconsistency, strengths, aspirations, and all that has led him to be who he is here and now. This goes beyond emphasizing the provision of quality services to those with mental health and addiction worries. Citizenship and belonging focus on membership within a particular network of relationships. Discrimination and marginalization can result in the person being "not of us" and outside the community or relegated to its impoverished and lonely margins, both of which are existentially cruel.

Another often overlooked communal factor focuses on expectations. Too often the general public expects too much of people with mental illnesses and addictions because they do not give adequate weight to the impact of the social determinants of health, stigma and the often discouraging chronicity and relapse of these illnesses. On the other hand, society can be overly paternalism and sympathetic such that too little is expected. Opportunities are not taken to encourage and applaud people's perseverance, kindnesses, resourcefulness, and lived expertise. Instead focus can be merely about psychological and behavioural symptoms of the illness and the prescribed therapies and treatments, not about the kind of person he is. 
He becomes defined by the illness. This ethically troubling reductionism explains why many eschew language such as "he is autistic..." or "schizophrenics are..." and instead speak about "those who are living with depression" or "he has a borderline personality disorder diagnosis or traits."

\subsection{Being a caregiver/provider}

There is empirical evidence that family and friends provide significant assistance and support for those with mental health and addiction problems. This often presents practical challenges if applicable legislation regarding personal health information prohibits disclosure to family members without the client's explicit consent. In most instances, mental illnesses are not yet curable; they are long-term health concerns. This means that family and friends are even more important in supporting someone through expected relapses. Some of these relapses can be highly damaging to these relationships: for instance, dementia often results in aggressive behaviours as well as dis-inhibition (e.g., undressing, frequent swearing, sexual remarks). Mental illnesses can result in frightening behaviours such as verbal, psychological, and physical aggression, loss of property (e.g., if a person has gambling problems or drives while impaired), and more. Therefore, family members may require emotional and psychological help to deal with their fears and distress as to the shared impact of the person's mental illness or addiction. Family members can become secondary "sufferers" of a particular illness or addiction.

The unique nature of psychiatrists' and therapists' work "[places] additional ethical demands on practice" (Radden \& Sadler, 2010, 59). Meaningful therapeutic engagement requires entering into the inner lives of clients, examining and often times challenging clients' interpretations, beliefs, self-image, fears and hopes. Clinicians may learn details that no other person in a client's life knows. In the name of safety, healthcare workers are permitted, often expected, to use governmental or police powers that will violate fundamental rights and freedoms. Accordingly, professionals' characters are very important. Radden and Sadler identify a considerable number of characterological virtues and offer detailed explanations as to why they are essential to the routine or everyday work of psychiatrists and therapists. The needed traits include trustworthiness, self-knowledge, integrity, empathy, warmth, sincerity, authenticity, unself-ing, "respect for the patient and the healing project," and more (Ibid, 136).

In forensic settings, a common concern is divided loyalties wherein professionals and healthcare teams are expected to prevent the individual from harming others and violating civil or criminal laws, and yet work with the person to build a therapeutic alliance to help recover from the illness or disorder. When clinicians are asked to assess a person for the court's purpose, it is essential that the person understand that the clinician is acting for the benefit of the court, not for her benefit. In this case, the overarching fiduciary responsibilities of physician-client or nurse-client are suspended to a certain extent. If the psychiatrist or therapist is unable to have a different relationship with the client in doing this assessment, it is ethically wise for him to decline to do the assessment. The general public often does not appreciate the inherent tensions between healthcare systems' and clinicians' roles and the judicial system and lawyers' / police roles, especially when the public's fears and biases are exploited by the media or by political interests. Yet the value conflict between these two systems is ethically necessary, as discussed in the sections below. 


\section{Why science, technology, and clinical factors matter ethically?}

Compared to many physical medicine interventions and programs, mental health and addiction services and treatments face added challenges that have ethical import. The following three issues clarify these challenges.

\subsection{Our knowledge about mental illnesses and addictions}

As Schmidt et al. note, "Definitions of mental illness tend to contain two aspects: a normative element and a functional element. Normative definitions delimit abnormal behaviour in light of what is typical, usual, or the norm.... [while] maladaptation suggests some diminished capacity to function relative to the average" $(2004 ; 10)$. Yet authoritative statements of knowledge and fact are fewer in psychiatry and psychology than in physical medicine. Individual experience and subjectivity still inform most psychiatric diagnoses. Scientific uncertainty continues, as illustrated by briefly describing the evolution of psychiatric classifications.

In 1948, the World Health Organization created the International Classification of Diseases (ICD). In 1952, the American Psychiatric Association (APA) published the Diagnostic and Statistical Manual of Mental Disorders (DSM), a short glossary of different psychiatric disorders based on psychoanalytic theory. This was considered a positive first step because various disorders were identified and publicized for the practice community's use. Yet the $D S M-I$ was not widely embraced because the disorders were relatively broad, the descriptions quite brief, and many practitioners were not Freudians. Sixteen years later, $D S M-I I$ was published, but the changes did not significantly resolve the first version's limitations. However DSM-III (1982) was different. It was reputedly not theoretically grounded. Instead, its diagnostic categories were based on observed and reported behavioural symptoms. It garnered praise from the psychiatric community because its multiple axes of contributing problems represented the disorders' complexity more accurately. Moreover, the categories and diagnostic criteria had higher inter-rater reliability (Pincus \& McQueen, 2002; Schmidt et al., 2004; Wilson \& Skodol, 1994). DSM-III-R (1987) included various clarifications and corrections. While DSM-IV (1994) was much like its predecessor, how it was created was particularly noteworthy: expert teams' consensus about each disorder was augmented by input from the psychiatric community at large as well as those involved in revising the ICD. DSM-IV also was based on scientifically stronger empirical (as opposed to anecdotal) evidence. Although DSM-IV-TR (2000) reflected no major revisions, it did provide various clarifications.

During this period, an anti-psychiatric movement emerged in the United States. One of its best known proponents is the psychiatrist Thomas Szasz $(2009 ; 1976 ; 1961)$. He contends that very few disorders are brain-based or organic. Instead, the majority of DSM-IV disorders reflect personal preferences that do not comply with social norms. As a result, these people experience difficulties in daily life. Those who feel that the harms of "mis-fitting societal norms" outweigh the benefits can, if they wish, seek assistance from other people to reduce or eliminate such difficulties. But since the maladies are not physiological, says Szasz, it makes no sense to seek physicians' and medical programs' assistance.

The anti-psychiatry movement endures today. In fact, some individuals and advocacy groups embrace the term "madness" as one way to counter what they believe is psychiatry's and medical institutions' illegitimate and hegemonic power and authority (Foucault, 1988; Wilson \& Beresford, 2002). 
The epistemic process of typological knowledge creation is often called nosology, or medical classification/categorization. Nosology continues to be an issue in mental health and addictions work because the questions still remain: "What makes something a mental [or addictive] disorder? and, Does this something form a category?" (Schmidt et al.; 11). In 2012 or 2013, the APA will publish the DSM- $V$. It will include a new framework or approach: dimensions, rather than mainly categories. There will be two general kinds of dimensions. First, clinicians' diagnoses will take into account the severity of symptoms, rather than mainly their presence or absence. Second, there will be "cross-cutting" symptoms, such as anxiety and suicidality, which occur in many illnesses. As a result, some disorders are expected to be de-listed and some new ones listed. In other words, some people will no longer have a psychiatric diagnosis, some people's diagnoses will be refined, and some will be newly diagnosable. Professional debate about the advantages and disadvantages of this new approach has been pronounced (Banzato, 2004; Collier, 2010; Helzer et al., 2007; Kraemer, 2007).

A similar debate is in progress in addiction treatment and care. Is an addiction to alcohol, tobacco, illegal drugs, or prescription drugs some type of disease, or a personal choice, or something else? The most popular alternative to the disease paradigm considers addictions to be more complex: they are the combined result of biological, psychological, and sociological factors. Researchers and practitioners differ as to which paradigm they believe is most accurate. But the ethical implications of this difference are real. People who develop cancer, psoriasis, or glaucoma are generally not considered ethically culpable for the loss of important abilities or for requiring publicly funded health services. If alcoholism is deemed to be a disease, then the alcohol dependent person may not be blamed for "having it." This is a welcome correction to the traditional moral condemnation of people with drinking problems. If responsibility follows causation, then a biopsychosocial explanation presumes something different. People's physiology, psychology, and social environment are presumed to be self-controllable and modifiable, albeit not totally. They are also presumed to be modified by other people's actions and inactions. Accordingly, if there are negative consequences, culpability for what could have been changed must be shared, rather than resting solely with the individual. The locus of responsibility relative to having an addiction matters ethically because it connects with the ethical concept of fairness. This concept of fairness, and more specifically equality and equity, helps determine the amount of publicly funded versus privately funded services individuals with an addiction problem should be able to access.

\subsection{Treatment and care}

Those who are not psychiatrists, psychologists, or addictions therapists may not realize how very diverse available treatments and therapies are. For instance, there are more than two hundred psychotherapies, clustered, for example, as cognitive behaviour therapy, family therapy, mindfulness, art therapy, psychoanalysis and more. This increases the uncertainty and complexity of finding the therapy that will benefit a particular person most or at least sufficiently. In the case of psychopharmacological treatments, they have had a checkered history. In the 1950s, new medications were hoped to provide effective and sustainable relief of illnesses' disabling symptoms... a promising change from the seeming unending-ness of psychotherapeutic counselling and from the irreversibility and extreme invasiveness of psychosurgeries. In addition to the physiochemical benefits, medications could also be 
administered without a client's cooperation or consent. This was not possible for psychotherapies. They could not be beneficial if the person was not in the appropriate stage of change and was not willingly engaged, irrespective of whether she or a substitute decision maker had consented.

The first generation of antipsychotic medications or "typicals" unfortunately caused too many people very serious and irreversible side effects such as tardive dyskinesia. The next generation of antipsychotic medications, the "atypicals," were expected to cause fewer side effects. While second generation drugs have helped many people, the long-term effects are discouragingly negative. For instance, individuals diagnosed with schizophrenia may develop diabetes due to some of these medications (Amiel et al., 2008; Lowe \& Lubos, 2008; Muench \& Hamer, 2010). Yet it takes years and millions of dollars to develop a new pharmacological treatment that can offer meaningful improvements, not just in terms of biochemical or physiological measures, but in terms of quality of life measures as well. The negative effects of medications, such as significant weight gain, slowed thinking, and sluggishness, help explain in part why people discontinue using them, only to find that they relapse into a serious state that may require emergency or involuntary hospitalization.

From the outset, funding of research of mental illnesses and addictions has been disproportionately low compared to funding of research of physical illnesses. In 2004-2005, for example, the Canadian Institute of Health Research devoted $7.5 \%$ of its $\$ 700$ million budget to mental health and addiction (Senate Standing Committee, 2008). Yet approximately $20 \%$ of Canadians have a mental health problem during their lives. In the same year, the U.K. spent $6 \%$ of its $£ 950$ million governmental health research funds on mental health (Kingdon \& Nicholl, 2006). In 2011, the American National Institutes of Health will allocate only $4 \%$ of its budget to the National Institute of Mental Health (National Institutes of Health, 2010). Consequently, available treatments and therapies are often less reliable and less specific than those for various medical problems. Moreover, more research funds are spent on pharmacological interventions compared to psychotherapeutic or alternative interventions, in part because the pharmaceutical industry spends almost as much as governments on healthcare research (World Health Organization, 2004). This means that new or more effective psychotherapies are less likely to be developed and that a proportion of research funds are used for economic purposes, namely improving a medication's competitive marketability and profitability.

\subsection{Daily practice models}

Different clinics and hospitals offer markedly different addiction and mental health treatments and programs (Finney \& Moos, 2006; Futterman et al., 2004). For instance, one addictions program's work may be guided by harm reduction principles. Familiar examples of a harm reduction approach are safe injection sites and methadone maintenance programs for ex-heroin users. Another program's work, however, may be guided by an abstinence model of treatment. Furthermore, what counts as harm reduction can differ considerably among clinicians (Miller et al., 2008). They may calculate the benefits and harms of a particular activity differently; for instance, providing information about different settings for alcohol consumption and their relative risks. Just as importantly, though, clinicians' opinions may differ regarding the morality of said activity. For example, accepting a client's decision to begin taking taxis during weekend drinking binges as harm reduction may seem 
to condone the client's wilful drunkenness. Some clinicians believe this clearly violates their professional ethos; others do not (Miller; 2008).

Models of care for mental health settings are also diverse: for instance, strengths-based, empowerment-focused, recovery, trauma-informed, custodial, rehabilitative, and sanctuary. As a result, how clients are seen and engaged by clinicians and teams will vary. A strengthsbased approach, not surprisingly, attends to clients' positive abilities to deal with and improve their health and circumstances. An empowerment approach emphasizes correcting historic and current power imbalances---typically profound imbalances---between people with a mental health or addiction problem and professional caregivers and their institutions or between these same people and society at large. The ethical concepts of agency, selfdetermination, voice, and liberation resonate with empowerment. A recovery approach focuses on a person's valuations, aspirations, interpretations, and pace and it adopts "the long-view" wherein recovery is acknowledged to be an ongoing and unfolding journey. As shown in Gagne et al. (2007) and Ontken et al. (2007) in relation to recovery, focal ethical values are narrative integrity, resilience, commitment, and fallibility.

It is ethically important to identify and understand the practice model relevant to a particular treatment situation because inherent ethical values can vary. In terms of a specific program's model of care, an ethics-related goal should be coherence among the model's foundational values, staff-client interactions, and the kinds of therapies and care offered. However, models can become out-dated as more is learned about what helps clients maintain and regain important activities and relationships, as other programs and systems change, and as certainty increases regarding what qualifies as mental illnesses and effective interventions.

Psychiatry, psychology, and case management qualify as "forensic" when they are applied to and used in our justice system. These include scientific and theoretical analyses of criminal behaviour, clinical and institutional/communal efforts to prevent or deter lawviolating behaviour, risk assessments and diagnoses for judicial proceedings, and police psychology. Ethically critical to this work is separating understanding why a person behaved in a certain way---in terms of "nature and nurture"---and morally judging him or her. Conflating nature and nurture or conflating biological processes and socializing processes typify anti-psychiatry's worries.

\section{Why law and regulations matter ethically}

It is sometimes said that mental health and addictions services and settings are dictated by laws and legal institutions, be they the courts, legislatures, regulatory agencies, prisons and jails, or the police. A common concern is that society uses its various powers for its collective interests to the detriment of individual or minority interests. This concern is historically accurate in many countries in terms of how they have responded to individuals with mental health or addiction problems. Too often, these responses were dictated by social norms for acceptable behaviours and appearances. If the behaviours or appearances violated these norms and rules, common responses were punishment, social expulsion, controlled quarantine, surgical interventions, and even death. However, there were often compassionate individuals and religious-based groups that countered societal edicts by offering agapic assistance and places of sanctuary to people seen as innocent sufferers of cravings or disordered thinking. 


\subsection{Rights and duties regarding decision making and consent}

Personal decision-making typically is one of the first ethical concerns in healthcare settings or issues, in large part due to the courts and legislatures. Today, healthcare involves many therapies and procedures, even in economically disadvantaged or developing nations. Most medical and nursing training programs now include seminars and discussions about clients' legally-protected rights to start, modify, or discontinue any intervention or service and the ensuing duties of professionals to honour such decisions. Valid consent---which authorizes a professional to act---is obtained when the person is informed about the particular intervention's benefits, risks, and burdens compared to other options, has the requisite capacity to make this decision, and is not being pressured, coerced or manipulated to decide.

These three components of the consent process can be obstructed or compromised by the nature or symptoms of mental illnesses and addictions. First, being informed. Healthcare workers frequently overlook this component when clients decline recommended treatments. This is why the consent process is shared: if a treatment is declined, the reason may be that personally irrelevant, non-meaningful, or unintelligible information has been unintentionally provided. Timely disclosure and intelligible explanations are among clinicians' routine duties. As per the clinical section above, our understanding of the nature and causes of mental health and addiction problems is relatively limited, though it is increasing. Accurate diagnoses can take considerable time and prognoses may be quite uncertain. Available therapies and treatments may be scientifically promising, but still lack sufficient high quality research studies to be able to provide highly reliable and nuanced details to patients. Consequently, clinicians can find it difficult to provide clients with individualized and useful information about their illness, prognoses, and personally beneficial treatments.

The second component of a valid consent process is having "enough" mental capacity to decide. When clients decline treatments, this component can garner disproportionately more attention from clinicians than the other two components. Governmental legislation often stipulates specific criteria that, if not met, mean the person lacks the legally required abilities to make his or her own health-related decisions. Two criteria often comprise legislated standards: (1) is the person able to understand the information, and (2) is he able to appreciate the consequences of having versus not having the intervention. These abilities can be undermined by mental illness or addiction. But no set of assessment questions or exercises qualifies yet as the validated set for accurate assessments. Consequently, different clinicians may assess a person differently in terms of having or not having capacity for a particular decision. Importantly, however, legislation and court rulings typically hold that someone who has a mental health or addiction problem can still have the needed capacity to consent to or decline a recommended therapy. In other words, depression, mania, paranoia, or hallucinations do not, in and of themselves, void the needed abilities to make treatment or other health-related decisions.

The third component is voluntary-ness. Certain therapies and care can involve social, environmental, and bodily control (e.g., group counselling, behaviour modification, protective devices). Coercion therefore is an ongoing possibility. Moreover, some mental health problems can result in a lack of self-control (i.e., mania, dis-inhibition) or in heightened fears (e.g., paranoid schizophrenia, having a history of trauma or abuse). This means that the invasiveness, demanding-ness or restrictive-ness of certain treatments may be very unwelcome, even though they can benefit the person in other ways. Furthermore, 
despite an appropriate substitute decision maker consenting to treatment on behalf of someone lacking capacity, it will still be traumatic and damaging to the therapeutic alliance whenever a treatment is administered against the person's will (e.g., with Security staff present, by forced injection, by forced application of a protective device to prevent selfinjury). Accordingly, before deciding whether an intervention fits with the person's prior expressed wishes and best interests, a substitute decision maker must understand not just the type of treatment recommended, but also how it will be administered and what will be the individual's likely experience of "being treated."

\subsection{Rights and duties regarding privacy and confidentiality}

Governmental legislation about the collection, use, and sharing of personally identifiable health-related information is common today. These acts, statutes and regulations protect citizens' right to privacy regarding their health, minds, bodies, and related activities by delineating professionals' and organizations' duties to keep such information as confidential as possible and yet use it effectively and efficiently. To preserve clients' and families' trust, limits to confidentiality and any legally required duties to report should be discussed as early as possible by healthcare workers. Later in this chapter, stigma and discrimination will be discussed in detail but suffice it to say that the need to protect mental health and addictions related information is especially important. The consequences of a person's employer and insurer learning that he or she has or has had a mental health or addiction problem can be significant and irreversible. This need to protect this information, however, can unintentionally frustrate, even damage, professionals' interactions and relationships with patients' families.

While many healthcare organizations include family-centeredness among their corporate values, this is more complex in mental health and addictions settings because family may have knowingly or more often, unknowingly, contributed to the person's poor health. Too often, family members emotionally, psychologically, and/or physically abuse one another. Yet research and testimonials show that people recover and sustain a good quality of life because of familial support. More strongly put, family support can be a protective factor (Cleveland et al. 2010; Ivanova \& Israel, 2006; Korol 2008; Piko \& Kovacs, 2010). Negotiating this quandary requires healthcare workers to have strong communication, interactive and assessment skills. Clinicians and healthcare organizations must be proactive in instituting practices to safeguard clients' privacy and to balance the competing interests of clients and their families without losing their trust or compromising their relationships further.

\subsection{Rights and duties regarding safety}

The political philosophy concept of parens patriae means that a legitimate government serves much like a patriarchal parent or father to its citizens. It is thus responsible for their general well-being and safety, and at times must make decisions that contravene their immediate wishes. A citizen may be in danger of being harmed such that those formally delegated powers to fulfill the government's duty (i.e., such as police and medical professionals) are expected to intervene on his behalf. So too if the citizen is harming or posing a serious threat to another innocent citizen. Governmental representatives may act unilaterally to stop or prevent such harm, especially if the potential victims may lack the abilities or resources to protect themselves. 
Mental illnesses and addictions can result in serious risks to the individual: suicide, selfneglect (e.g., poor hygiene), self-harm (e.g., cutting, pulling out hair, repetitive scratching). Governmental powers to hospitalize, restrain, seclude, or treat against a person's wishes, when her behaviours are due to mental illness, are often legally set out in mental health legislation. The same legislation will specify who is legally obligated to forcibly act against the person's wishes when other people could be harmed or at risk of harm by her due to the mental health problem. If there is no actual or suspected mental health problem, then the individual would be dealt with according to applicable civil or criminal laws. Questions about the kind (physical only or psychological too?), the probability, the urgency or imminence (within the next few days or longer?), the seriousness or significance (lifethreatening, disabling and/or dignity-threatening?) arise when such legislation is written or revised. While mental health legislation in most jurisdictions agrees that governmental intervention is warranted when death or serious physical harm is likely, there is disagreement as to whether other harms should be unilaterally and forcibly prevented. Similar questions arise in healthcare settings when healthcare workers, family members and the police try to decide whether to invoke their government-delegated powers.

Governmental legislation should try to strike a balance between the safety of the individual and others and the magnitude and duration of restrictions imposed upon the individual. Which rights and freedoms enjoyed by other citizens will she lose and for how long? What are the least invasive and limiting options? These questions probe whether the response to her harmful behaviour focuses on maintaining safety or on punishing undesirable behaviours.

\subsection{Institutional mechanisms}

Punishment is a worry for mental health facilities because their competing goals include keeping individual clients safe and keeping others safe. There are four theories of punishment: retributive theory, deterrence theory, rehabilitative theory, and restorative theory. The last three of these theories happen to resonate with various clinical paradigms. Such coherence can unintentionally link punishment with clinical interventions. It is crucial for clinicians and teams to focus on the behaviours and decisions that relate to the health problem for which the client is seeking therapeutic help. Interventions and accompanying interactions must not be punitive.

A recent judicial trend is the creation of "mental health courts" and "drug treatment courts." Their objective is to divert those who have been found guilty of violating certain laws, albeit as non-violent crimes, away from prisons and jails. The mitigating factor in this sentencing is that these people broke a particular law because of a mental illness or addiction. The fact that someone has a mental health or addiction problem does not mean that all his or her actions and choices are determined by the problem. To qualify for "medical diversion," the law-breaking actions have to be the result of the health problem; for instance, the person's judgment was impaired because he or she was intoxicated or responding to paranoid thoughts or to threatening internal voices. Accordingly, a judge decides whether the person should be diverted to an appropriate health facility to receive treatment and care for the mental health or addiction problem. Historically, judicial systems have provided no or minimal mental health and addictions treatment because punishment and control were the priorities and funding was inadequate. Focused, integrated, and sustained treatment in hospitals' programs is expected to help these individuals return to the community more 
quickly and not re-offend. Those who are directed to mental health and drug treatment courts usually can choose to have their cases heard in "regular court" with the possibility that if found guilty, jail, prison or probation is next. However it has been found that those who agree to be diverted into the health system may be under its auspices longer than if they had been in jail or prison. It can seem that diversion is harsher and thus less fair. This harkens back to the lack of highly effective, of easily sustained therapies or of adequate community services to justify a conditional discharge.

Therapeutic jurisprudence is a concept first coined by David Wexler, a professor of law and psychology, in a $1987 \mathrm{NIH}$ conference paper (Corvette, 2000). He held that judicial systems and processes can be beneficial or harmful to those who break civil or criminal laws. Being held responsible, treated fairly, assisted in exercising rights to a fair hearing as well as others having duties to follow the impartial rule of law are considered to be psychologically and existentially affirmative of the individual as an equal member of the community. Moreover, the judicial system can help mediate injustices experienced in the public realm: "Therapeutic jurisprudence is normative. It suggests that to the extent possible, consonant with due process and justice values and goals, undesirable effects should be avoided or minimized and positive effects should be maximized" (Ibid, 103). Therapeutic jurisprudence fits with mental health courts and drug treatment courts to a degree. These court settings bring together employees of two major societal endeavours: the judiciary and healthcare. Nevertheless, caution is warranted. Various legal scholars and academics worry that these employees' roles will illegitimately merge such that role boundaries are crossed. In other words, the judicial employees will weigh in too far---beyond their knowledge and training--into the work of the healthcare employees and vice versa (Dickie, 2008; Moore, 2007; Nolan, 2003). Furthermore, benefits vary between women and men. This, in turn, warrants increased study as to different stakeholders' views about the meaning as well as the effects of these courts and their processes (Hunt et al., 2007; Moore, 2007; Shaffer et al., 2009).

Similar debates have arisen when legislatures have considered amending existing mental health laws to include community treatment orders. These orders, often called involuntary community treatment, are meant to organize a mixed set of supportive community services so that a person can leave the hospital and live safely in the community as a less restrictive option. If, however, the community providers and agencies do not fulfill their responsibilities and it is possible that the person will become unsafe as a result, then he can be forcibly re-hospitalized forthwith. At issue is how to ethically evaluate this option: solely on probable consequences (e.g., fewer urgent hospitalizations, shorter hospitalizations)? At present, not enough is known as to why community treatment orders are associated with certain positive outcomes. Are they due to the ongoing availability of comprehensive supports or is it due to the ever-present threat of the client being re-hospitalized against his will? (Burns \& Dawson, 2009; Hunt et al., 2005).

Mental health and addictions settings encounter another challenge in the guise of advance directives. Advance directives have been discussed for years in the context of physical, acute care medicine. Medical advance directives permit people to designate who will be their healthcare decision proxy and/or to provide guidelines for subsequent decisions when they no longer have the capacity to decide on their own behalf. Empirical evidence shows that psychiatric advance directives, or "crisis cards" in the U.K., reduce the frequency and length of emergency hospitalizations. They also increase clinician-client trust (Srebnik \& Russo, 2008; Sutherby et al., 1999). Yet discussions about psychiatric advanced directives' usefulness often ignore a critical detail: can directives be invoked before persons satisfy 
legislated criteria to be deemed incapable? Or can they be invoked only after they are assessed as lacking capacity? The "after" scenario is not too ethically or legally controversial because the directive actually constitutes client participation in the care plan and establishes relevant "prior expressed wishes" (Bogdanoski, 2009; Srebnik et al., 2005; Swanson et al., 2006). Dubbed "a Ulysses contract" after the Greek fable about Ulysses, the "before" scenario is definitely controversial. If there are legislated standards and court rulings to protect decision-making by capable citizens, then it could prove difficult, perhaps legally impossible, for citizens to waive their right to such decisional protection.

\section{Why organizational context matters ethically}

In the early decades of bioethics inquiry, academic and professional scrutiny and debate centred on the work of researchers using human subjects and "bedside" or "front line" practitioners. The issue that expanded this focus to include administrators, management and executives, and Board members was, I believe, the galloping costs of healthcare services that were not adequately reimbursed by governmental and private insurance plans. In the United States, Medicare's and Medicaid's decision in the 1980s to shift from reimbursing as per diagnostic Related Diagnostic Groups and to capitated managed care costs confirmed the immense impact of management on client-professional relationships. Moreover, increasing annual deficits made the business of healthcare an issue for everyone, from patients, practitioners, hospitals, commercial employers to governmental health ministers. All economically developed nations now experience demand exceeding healthcare supply, despite increasing budgets. Continued technological advances are typically more costly and citizens' confidence that "new" and "more" produces better health outcomes is often shortlived.

An "organization" will herein be defined as a designated group of specially trained or skilled people working towards a shared goal or purpose. As such, a rural adolescent drug counselling office consisting of three addictions workers and an office administrator constitutes an organization, as does each discrete unit within a psychiatric hospital, as does the hospital as a whole. Organizational considerations are not the concern or responsibility of only executive management; they are the responsibility of virtually all staff members.

\subsection{Organizational factors}

Organizational considerations in healthcare fall into four general categories, each of which warrants a brief explanation as to its relevance for ethical practice in mental health and addictions settings. One category is the ethics of the organization's mission or mandate. The purpose of an organization, irrespective of whether it has been formally and explicitly described or it is implicit in its regular activities, establishes to whom the organization is responsible and accountable and for what... and to whom it is not responsible. More simply put, a mandate sets out the groups of people to whom the organization must respond with "Yes, we can help you" and to whom it can respond legitimately with "You will have to look elsewhere for assistance." In contemporary healthcare, healthcare organizations have often developed a set of values to guide how their mission and strategic goals are accomplished. A point in this chapter's introduction bears repeating here: some values are intrinsically ethical (e.g., being trustworthy, relieving suffering). Other values may be instrumentally ethical (i.e., financial stewardship so as to maximize number of clients served). 
A second category is the ethics of how a healthcare organization is governed: what should be the guiding operational standards and according to whom? Governance will be both internal and external. Examples of external governance include accreditation standards, employment and occupational health regulations, applicable government legislation, funding regulations, professional Colleges' codes of practice, and the organization's Board of Trustees/Directors. Examples of internal governance include negotiated labour contracts, a code of employee conduct, quality-safety committee, any document that details patient rights as well as the largest and most endemic "repository" of internal governance, written policies and procedures.

Another general organizational ethics category for healthcare settings is the ethics of resource acquisition, allocation, and disposal. Here, "resources" applies not just to money, but also to staff, beds, counselling sessions, equipment, physical space, and professionals' time. How resources are obtained is ethically important, as evidenced by debates about seeking funds from pharmaceutical and gaming corporations or about recruiting nurses and professionals from countries sorely lacking in qualified personnel. Allocation of resources, as mentioned earlier, is the most well known organizational ethics issue in health care: how to allocate resources fairly, even if there is just "soft" scarcity, is challenging and often is informed only by an implicit utilitarian calculus. Prioritizing access to and provision of inpatient or out-patient services occurs routinely and includes wide-ranging decisions such as which medications to include or exclude from a hospital formulary, how to respond to "VIP requests" for access, and how many times a hospitalized client or his substitute decision maker can decline a community bed without consequence. Resource "disposal" first came to attention vis-à-vis discussions about the environmental impact of what was being discarded by tertiary, acute care hospitals. Yet closing or reducing services can mean staff layoffs and reduced hours. Refreshing all computer hardware can mean deciding whether to donate the replaced computers to a remote school or a community centre serving people living with addictions problems. "Disposal" decisions involve ethics-related values such as who will be harmed versus benefited, who should help identify alternatives and applicable rationales, and who is responsible for making the final decision.

The last category is the ethics of an organization's culture and climate. Understanding what culture and climate are and their impact has been a favoured topic in business ethics and business literature for some time. Culture is reflected in what is considered acceptable versus unacceptable behaviour and interactions. It is so ingrained and presumed to be "right" that it does not need to be written anywhere. Culture will include norms for how hard staff should work, what counts as humour, what questions can and cannot be asked out loud, and how much is decided by committees versus individuals. Climate is a metaphoric word to capture the organization's current mood: is it optimistic, such that trying something new without administrative permission is a safe thing to do? Or is it suspicious, such that "not rocking the boat" is well advised? Or is it celebratory such that being a little less productive for awhile is acceptable?

In virtually all ethics related questions involving clients, organizational considerations will implicitly or explicitly impact their treatment, care, and interactions with co-clients, staff, family members, and outside parties. In some instances, staff responses will be ethically weaker or stronger because of these considerations. Some everyday examples include practices and policies about smoking restrictions, searching clients' belongings, hospitalized clients' intimate and sexual behaviours, clients' use of illegal substances during the therapy period, staff responses when clients may be driving impaired, staff obligations or lack 
thereof if a pregnant client uses illegal substances, and so on. Policies and practices must balance competing, often conflicting, interests and responsibilities. As noted by Winkler (2005), depending on how policies are developed and implemented, they can minimize the power and resource imbalances among staff as well as between clients and staff. Or they can exacerbate them. As memorably explained in Skorpen et al.'s (2008) article about smoking rooms in a psychiatric facility, clients can try to find ways to regain power and equal status. On a separate but related point, safety initiatives will be ethically grounded. However, safety can become the "sun" that blocks out all other considerations, or "a trump card" that silences all other interests and voices. Depending on a healthcare facility's culture and climate, it may be politically unwise to suggest that safety measures are causing more burdens and disadvantages than anticipated.

Busy clinics and hospitals may operate unintentionally in ways that traumatize or retraumatize clients. Many people who develop a mental health or addiction problem have experienced serious trauma, be it physical, emotional, and/or psychological abuse. If a medical office or health clinic's practices are impersonal, coercive, or disrespectful, the person may find them even more distressful and stressful because her past experiences of being silenced, pressured, or shamed are remembered and reinforced. Moreover programs and units may operate with such allegiance to "the rules" that professional judgement and integrity fade. Having integrity requires some modicum of inner struggle, according to scholar Stephen Carter (1996). In other words, having integrity is praiseworthy because it is hard to achieve. Therefore if healthcare workers' motives for acting as they do come from "following the rules," then they might be commended as being capable rule followers, but this is divorced from being professional or having integrity. As noted in the introduction, reasons for acting may not be based on ethics-related values, but instead on other considerations such as self-interest, convenience, power, or fatigue.

\subsection{Forensic programs and services}

The ethical challenges and complexities of forensic healthcare programs and settings are numerous and significant, as reflected throughout this chapter. In the case of forensic services, care is needed to avoid unintentional "creep" of the police and prison system into the therapeutic system. Language is an obvious marker of such ingress: clients or patients have privileges that they can lose, regain, and exercise. Yet the word "privileges" evokes imperialism and parentalism because privileges are granted by one party to another. If an empowering or strengths-based approach is adopted instead, clinicians could refer to a client's "responsibilities" or "actions" as set out in the court or review board order. There would be consequences, positive and negative, if she fulfills or does not fulfill her responsibilities, rather than the moralizing or infant-alizing rhetoric of "consequences to reward good behaviour." To help balance the power relations more equitably, her clinical team and the program management would also have various responsibilities to fulfill. Another example is contraband, wherein clients are prohibited from having certain qualifying items with them in the hospital. But "contraband" is a familiar police and drug enforcement word related to smuggling. It does not belong in a healing environment (recall that the person was diverted from the prison or jail system). Alternative wording could be "unsafe items" or "prohibited items," which are accurate descriptions but far less polarizing. Ethics texts written for psychologists and psychiatrists usually include a chapter on ethically defensible ways to formally assess a person for court such that the person does not 
mistakenly presume the clinician has her best interests in mind. As noted above, health workers may struggle to maintain the appropriate balance between offering therapy and following a court's legitimate demands. It is essential for programs to proactively and openly examine their routine practices. These forums will help support workers to deal with the to-be-expected moral distress of meeting competing commitments (Austin, 2001; Morse, 2008; Pouncey \& Lukens, 2010). Moreover understanding clients' actual experiences of these situations, rather than just working from assumptions, is important because the significant power differential between clinician and client can progressively erode professional commitments.

\section{Why systemic factors matter ethically}

Since moving from a large tertiary, acute care hospital to working at a large mental health and addictions hospital, systemic factors have figured prominently in my ethical analyses and recommendations. Like Sokol, I gradually became aware of these factors' impact on the daily lives of clients, families, and healthcare workers alike as I listened to more and more personal stories: someone who can only afford substandard housing and worries bedbugs will soon infiltrate their belongings, a recreational therapist frustrated that clients are not welcome at a community gym, and rural parents whose employer-paid insurance plan caps psychotherapy for their behaviourally aggressive child at ten sessions per year. Systemic factors are implicit in a community or society's ongoing activities that occur just outside the walls of a private practice, clinic, or hospital. Three kinds of factors are particularly relevant to defensibly determining normative responses or, in other words, "what should happen." Moreover these factors ground any health and healthcare decision in the reality of a particular society or community. Sidestepping these factors in ethics-related analyses can result in ineffective responses or assigning responsibilities disproportionately.

\subsection{Stigma}

The first ethically weighty factor is stigma. There are many definitions of stigma, but Jo Phelan and Bruce Link (2001) offer a nuanced characterization. They suggest that it has four components, which appropriately captures its complexity: (1) human differences are identified and labelled, (2) these differences are linked to negative qualities, (3) those who are different become "Them" as separate from "Us", and (4) the person's or group's social status declines and unfair discrimination occurs. Those who make up society's majority, captive to the seeming truth of "bell curve statistics," commonly presume that what is common constitutes what is "normal" and what is uncommon constitutes what is not just rare, but also what is morally abnormal. As described by historical accounts of societies' treatment of those whose thinking was unusual, this treatment has traditionally been fearbased and repressive. Furthermore, if people's thoughts were accompanied by behaviours and appearances that violated social etiquette and norms, the collective responses included dismissive marginalization, controlled quarantine, or forced treatment. Historically, mainly charitable or faith-based institutions endeavoured to care for and about people with mental illnesses until the past fifty years or so in North America and Europe. Yet stigma remains a contemporary problem. For example, based on its 2006 Senate report on mental illnesses and addictions and available services, Out of the Shadows at Last, Canada's Mental Health Commission launched "Opening Minds," a ten-year anti-stigma/anti-discrimination initiative. 
Social or communal stigmatization and discrimination----related to ethics concepts of dehumanization and injustice----help explain why most people are initially reluctant to seek psychiatric and psychological testing because of the enduring harms of being labelled as having a mental health or addictions problem. Families, too, delay seeking information and help from clinicians and programs, often relying primarily on the Internet's anonymity and non-judgemental-ness. Keeping health problems secret limits access as well as limits offers of needed, physical, psychological, relational, educational, and economic support. Yet stigma and discrimination go beyond the general public's response to those living with a mental health or addiction problem. Studies have also revealed that many mental health and addictions workers unconsciously and consciously stigmatize and discriminate against their own clients despite their day-to-day interactions with them (Flanagan et al., 2009; Liggins \& Hatcher, 2005; Ross, 2009; Schulze, 2007). There is also evidence that mental health and addiction workers themselves are stigmatized by working in this field of healthcare (Gouthro, 2010; Halter, 2008; Stuhlmiller, 2005).

Discrimination of individuals with mental health and addictions problems can be more subtle, but can be just as unfair. It is important to examine whether double standards are being presumed or relied upon. Clinicians and teams may want to restrict client activities that would be permitted in general society. For example, a residential program may decide to permit residents to engage in consensual, non-exploitative intimate behaviours in their private rooms, but expect these behaviours to reflect "highly responsible" or "meaningful" activity. Or the program may have a search policy that presumes residents to be more dangerous and more devious than has been actually experienced. Media stories and mainstream television and movie companies sensationalize rare disorders and behaviours as well as behaviours that result in criminal charges or convictions. For instance, programs and healthcare workers' attention can be disproportionately directed to people's use of illegal drugs compared to their tobacco and alcohol use. Yet smoking and drinking alcohol cause more death and serious co-morbidities than marijuana, or even heroin.

Language is slow to change, too. Someone in treatment for, say, cocaine addiction is said to "test dirty" on a urine drug screen (Radcliffe \& Stevens, 2008; Rose et al., 2005). Urine screens for people with diabetes, however, are described as "testing positive" or "negative.". As "addicts," "schizophrenics" or "sex offenders," people are reduced to a particular illness or behavioural category. There has been a move within the addictions field to talk about substance dependence, misuse, and abuse... rather than always about addictions. Hofman et al's 2003 study of inner city women who were IV-drug users and used outreach health services far less than male IV-drug users in the same area revealed the women's ongoing efforts to fulfill familial and communal responsibilities plus retain a sense of respectability. The criticism of healthcare workers' continued use of the demeaning and paternalistic terms "compliance" and "non-compliance" is about stigma as well (Acosta et al., 2009; Bissella et al., 2004; Proulx et al., 2007; Stewart \& DeMarco, 2010). Because of stigma, discrimination, negative side effects, and human nature, it should not surprise us that people do not follow prescribed regimens at the high level of "compliance" needed. As noted by a systems and client advocate, those receiving health services do not set a personal goal of "being more compliant" with their treatment (Jennifer Chambers, 2010; personal communications). Instead, they set more meaningful goals such as getting sustainable employment, feeling well enough to help with a son's homework, or having more faith in one's hard-won wisdom. 


\subsection{Social determinants of health}

Being healthy does not rely solely on physiology, genetics, and lifestyle choices. Social and cultural factors also have significant impact (Lauder et al., 2007). While the World Health Organization (2003) identifies several social determinants, three are of particular ethical import for mental health and addictions contexts: housing, unemployment and poverty, and social isolation. The percentage of people who are homeless and have a mental illness, while difficult to accurately determine, is estimated to range from $20 \%$ to up to $50 \%$ in various studies of Canadian, U.K. and American cities (Hwang, 2001; Meltzer, 2008; National Coalition for the Homeless, 2009; Neale, 2008; Senate Standing Committee, 2006). The relationship between unstable and inadequate housing and mental illness and addictions is considered to be bi-directional. In other words, sub-standard housing contributes to onset or relapse just as mental illness and addictions contribute to loss of adequate and reliable housing. Reflective of continued discrimination, "NIMBY" or "not in my back yard" is a common community response, opposing governmental or private agency housing initiatives for people with persistent health concerns, such as mental illnesses and addictions.

People with mental health and addictions problems are at increased risk of living in poverty (Canadian Mental Health Association, 2007; Hudson, 2005; Wilton, 2004). Schizophrenia, for instance, usually manifests in late adolescence or young adulthood, which means educational efforts are disrupted. Lack of post-secondary education usually results in being less competitive in the job market. Stigma means that finding suitable employment is more difficult---even though many countries have legislation prohibiting discrimination based on health conditions---and once employed, people must often be diligent to keep their mental health or addictions history secret. Governments may offer financial assistance to those unable to work due to a physical or mental disability, but the amount of support typically provides for a low standard of living.

Psychiatric hospitals were once known as "asylums" because they were considered safe havens from the uncertainties and rigors of daily life. But too many became immense institutions of sturdy walls and high fences in which people with mental health problems lived out their lives separated from the community. Exclusion is anathema to human health and well-being. Moreover, some mental illnesses, such as autism, paranoia, and personality disorders, involve reduced abilities to understand or trust other people and this, in turn, undermines relationship-building. Add public prejudice and the consequences for many people with mental health problems are isolation and marginalization (Baum et al., 2010; Elisha et al., 2006; Morgan et al., 2008 and 2007; Smith \& Hirdes 2009).

\subsection{Health and social systems writ large}

The third systemic factor that is ethically noteworthy is our social and health systems. Three issues help illustrate the tangible impact of these systems on the therapies available and the recovery realized. First, ethically worrisome conflicts of interest can exist. When a government sells alcohol and operates gambling venues (e.g., casinos, lotteries), this runs counter to its public health mandate (Andresen, 2006; Livingstone \& Adams, 2011; Walker \& Jackson; 2011). Even if a government only regulates commercial sales of these items and activities, their coffers receive immense sums of money from luxury taxes on alcohol, gambling, and cigarettes. As evidenced by the "Big Tobacco Settlement" in the United States, only a few of the 48 states in the class action suit directed a substantial part of their proportion of the $\$ 235$ billion settlement to smoking prevention and treatment. The other 
states assigned their settlement portion to deficit reduction, infrastructure needs, and more general uses (Johnson, 2004).

Another systemic issue is the historic and continued unfair insurance coverage or reimbursement for non-physician and non-hospital therapies. For instance, Canadian provincial and territorial governments' health insurance plans tend to not reimburse psychotherapies or alternative treatments provided by non-physicians in the community, but do reimburse physician-provided/prescribed and/or hospital-based treatments. In most cases, psychologist/therapist and psychological measures are either paid by employer insurance plans or out-of-pocket (Parker \& Burke, 2005). These plans usually cap their coverage at low levels. In fact, the U.S. Congress passed the Mental Health Parity and Addiction Equity Act in 2008 to help address this inequity by requiring federal health plans to reimburse mental health services on par with medical health services.

Systemic considerations contribute to "revolving door situations," which are usually and unfairly identified as "revolving door patients." These situations centre on health gains, made by someone while receiving the intensive and publicly provided services in a hospital, dissipating quickly once he returns to the community which may lack certain services, or have insufficient services, or have services that are neither easily understood nor effective. Continuity of care and comprehensiveness of services falter. As a result, he soon requires rehospitalization to receive more intensive and comprehensive therapies. Returning to home may mean that the benefits prove unsustainable and re-hospitalization is likely. This repetitive cycle is particularly concerning if the illness is such that it is not physiologically possible to return fully to the pre-crisis levels of functioning. Health system reform and social system reform appear on most countries' election platforms, but reform is difficult to achieve given the programs' immense complexity and the perpetual expectation of increased funding.

\section{Conclusion}

\subsection{Cases revisited}

How can these various recommendations and cautions deepen and refine our understanding of the cases at the opening of this chapter and shift our responses from what is minimally ethical to what is optimally ethical?

Case 1: First, the nurse should verify what the applicable legislation states in terms of which, if any, healthcare professional is responsible for reporting what, to whom, and based on what evidence. If the legislation does assign responsibility, is it to just a physician or to any healthcare worker who has direct contact with a client? If to a physician only, is the nurse legally expected to notify the physician? Is the responsibility framed as obligatory or permissible? In terms of evidence, is it in the form of a professional assessment or a mere belief or opinion? Answers to such questions should guide the nurse in terms of what she says to the physician and what she and/or the physician say to Sergei.

Even if there is no applicable legislation, this remains a possible health concern that the physician should broach supportively with him. Alcohol dependence rates are highest in Russia, therefore it is more likely that he, too, has a substance use problem, or at the very least, may be experiencing some personal challenges for which he is misusing alcohol to cope. If the physician and/or nurse conclude they do have a legal duty to report, it remains their decision as to whether they actually will contact the Ministry. They may decide instead to talk first with Sergei, learn more about his drinking pattern and motivations, and inform 
him of their legal obligation to report. In so doing, they are weighing the likely consequences to Sergei, his family members (who may be in the car when he is impaired), and the general public. They may also believe openness and support will help preserve their therapeutic relationship with him and increase the likelihood that if he is misusing alcohol, he will pursue treatment and/or counselling. If the clinicians report Sergei to the Ministry and the Ministry decides to revoke his licence, they should be willing to support---if they have relevant corroborating information regarding his successful efforts to control the medical condition that resulted in dangerous driving---a license re-application in the future. Case 2: A team member should find out exactly what the Mental Health Act states. It is careless and unprofessional to rely on unfounded assumptions and beliefs. The harmfulness of sexually transmitted diseases (STDs) is subject to debate. For instance, some STDs are not reportable under any provincial or state public health regulation, some are reportable only in certain jurisdictions, and some STDs are reportable in every jurisdiction. Moreover, is involuntary hospitalization the least restrictive preventive measure? The team may be illegitimately presuming that Ana Li herself considers pregnancy or an STD something to prevent. Paternalism needs to be tempered as do any moral judgments about "unwed mothers," "inadequate mothering," or promiscuity. It is unclear whether Ana-Li lacks the capacity to be making decisions about measures to reduce the likelihood of STDs, pregnancy, or about engaging in sexual activity. Hypersexuality alone does not imply incapacity. The team must share their concerns with Ana-Li and do so in a sensitive and mature way. It should not be assumed that all team members are experienced and skilled enough to talk about sexuality and intimacy.

If, however, she is found to lack the capacity to make decisions about such preventive measures, the team should turn to her mother to make the related medical decisions. The team will need to be more skilful in their discussions with Ana Li's mother so that it will be the client's values that are respected. It is to be expected that parents and young adults will differ about the meaning and risks of intimate activity and pregnancy. Admittedly single parenthood tends to be difficult financially and otherwise, but this is often due to societal constraints, rather than the individual's apathy. Diligence is needed to not lapse into double standards wherein most parents are given considerable latitude yet those with mental health problems must reach a far higher standard. It would not be surprising if a team member suggests early notification of a local child protection agency because of the possibility that Ana-Li could become pregnant and unable to care for a child. However this is a "rush to judgment" and may reflect prejudice and disrespect. Moreover, once the call to the agency is made, it cannot be "unmade" and Ana-Li's name may be recorded in its system indefinitely. This could be stigmatizing and may negatively affect her in the future.

Case 3: The program clients' health should improve and be sustained longer by having peer workers' support and advice and by having staff understand how their homes (or more often, "housing") contribute to or erode their well-being. Team members should benefit professionally as well, because peer workers' knowledge can help counter over-reliance on the medical model and home visits help members identify and tailor services better to clients' circumstances and thus be more effective. But clinical considerations---which relate to ethics because they are about meaningful benefits for those involved---do not exhaust this case. A peer support worker can be a very special role: for instance, it may be designed such that workers do not "do" therapy or provide treatment. Nor do they fill in for absent family or friends, helping to occupy clients' free time. Instead, peer support workers have their 
own expertise and ways to support clients in being as healthy as they wish. Team members may unintentionally induce peer support workers to take on their work and thereby violate role boundaries. Peer workers themselves may be attracted unconsciously to the seemingly greater authority of the professionals, especially if the workers work side-by-side with the clinic or hospital staff. These are organizational considerations.

Ethically, power, authority, and voice are involved here which means that client trust of the team and workers is at stake, just as is the trust between the team and the workers. The initiative about home visits is ethically complex because some clients may prefer to keep their homes private, away from the team's "medical gaze." Other clients, however, may appreciate home visits because of the convenience, plus it may help equalize the power in their relationship with team members. Team members may not appreciate this implicit loss of power. And if client lives in a risky area of town, team members may be reluctant to visit alone, but program resources may be heavily strained if staff make home visits in pairs. Nonetheless, equity of access to healthcare services demands proportional efforts (greater efforts if access is harder) to reach those living in inhospitable areas due to poverty resulting from having a serious mental illness or addiction, compared to efforts to reach those living in safer areas. Neither initiative should be unilaterally imposed on clients, despite how clinically sensible the initiatives seem. The director, managers, and leads should seek input from a representative group of clients to ensure that both initiatives fit clients' circumstances and needs well. Furthermore, since the director is new to the program, he must act in trustworthy ways in the hope that all his staff will genuinely commit to his overarching vision, of which the two initiatives are representative.

Case 4: It may not be ethically sufficient for someone with good oratory skills to speak on behalf of Jane. Given the historical treatment of individuals with mental health problems, providing them opportunities to use their own "voice" can signal respect and a better equalization of power. Moreover, the team should not assume that their therapeutic relationship with Jane is more important than her relationship with the lawyer. Exercising one's legal options and participating in the judicial system are valuable citizenship rights. The team may also be presuming incorrectly that the lawyer did not explain to Jane the possible pros and cons of her testifying and how the Board would likely interpret her remarks. Moreover, Jane may have decided that the benefits of speaking---to affirm her courage to "stand before" those who will judge her case and to have them listen to her--outweigh the possible risks. Team members may be ascribing to an erroneous stereotype wherein Legal Aid lawyers are believed to be less skilled than Crown attorneys and corporate lawyers. At the outset of Jane's hospitalization, the team should have discussed with her what their responsibilities are to her, to the Review Board, and to her lawyer, and any competing, possibly conflicting, commitments. Leaving such conversations until just before a Board hearing is inappropriate. The team should encourage Jane to see them and her lawyer as available resources to her to help her return to the community, but refrain from telling her what she should do to receive a conditional release.

Case 5: Is Omar revoking his consent when he says he does not want to go to the specialist? If "yes" but the team ignores the revocation because debridement is "clearly in his best interests" and his ulcers are debrided, this would constitute assault. What if the team concludes that at the time he says he does not want to go, he lacks the capacity to decide against debridement? Does his prior agreement when he had capacity still apply? This situation illustrates the telling difference between consent to treatment---a decisional 
activity---and cooperation with treatment---a physical and behavioural activity. Trying to take him to the specialist's office may result in an escalating situation of angry words, raised voices, threatening statements and then a "code" has to be called. This may damage the therapeutic relationship such that when Omar regains capacity, he may decide that returning to his home as quickly as possible is his best immediate option. Furthermore, Omar's refusal to go to the hospital may reflect many people's common reluctance and vacillation about seeing medical practitioners and therapists. Understanding clients' statements and behaviours should not be reduced just to medical considerations (i.e., noncompliance) or legal considerations (i.e., lacking capacity). Rather, it is crucial to see clients first as everyday people with many similar habits, preferences, and interests as everyone else. In other words, Omar's wish to not go to the specialist may be the response of most people who must go to big hospitals or have non-healing ulcers debrided. Those who are not in a hospital would just phone the specialist's office and ask for a later appointment. But Omar is in the hospital. The clinical team are now involved and may be unknowingly making it their care plan, rather than his care plan.

Case 6: Money can compromise organizational and personal integrity and reputation alike. The representatives should generate a variety of ideas to cover the costs without sacrificing the number who will attend or who can attend. The considerable profits of pharmaceutical and alcohol businesses means they have ready resources to increase their name recognition and brand loyalty. The agency representatives should find out what are the kinds of restrictions or limits academic healthcare institutions---which have long worried about conflicts of interest, unbalanced content, and reduced credibility---have instituted in terms of financial support from commercial enterprises and use these as guidelines. Moreover, it is worthwhile investigating whether the industries have set their own detailed guidelines for donations. As illustrated by the Code of Ethical Practices of Canadian research-based pharmaceutical companies (Rx\&D, 2010), industries may want to avoid perceptions of excess and undue influence in order to protect their corporate reputation. In terms of the lottery, will it increase attendance enough to cover the spa's cost? Can the lottery be replaced by a draw wherein all registrants receive just one ticket? If the spa weekend is of modest value, it is unlikely to lure those with gambling problems. And much time will pass between registration and the draw, which means immediate gratification from winning, a risk factor of problem gambling, is almost impossible.

Case 7: Keeping secrets is risky, whether the secret-holder is the person with the health problem, a family member, or a clinician. In the short-term, the benefits of secrets may outweigh harms. Nonetheless, it can become more and more difficult to keep them. The harm of nondisclosure may increase as time passes. The "right time" to break the silence about the secret may never appear, but Edward's health problem is long-term. Moreover, what explains his continued visits to the physician? And what explains the seeming inconsistency between taking the renewed prescriptions and yet not having them filled? Qualitative studies have revealed that people have sound reasons for what appears initially to be noncompliance with the recommended treatment.

In terms of Sandra and her partner, they should not be expected to keep their home open to Edward indefinitely. Women continue to fulfill most of the demands of family and home life in most societies, a continued sign of societal discrimination. It is thus inappropriate for the physician to presume that Sandra and her partner still want to or should have Edward reside with them. To address this quandary ethically, the physician should let Sandra know 
that it is not, and was not, legally or ethically appropriate for him to take advantage of the secret administration of the prescription medication. He can suggest that Sandra explain to Edward what she has done and why and be supportive if she is worried that Edward will react in a threatening or unsafe way. The physician should invite Edward to his office to discuss what has happened, why and provide information and resources to help Edward remain as healthy as he wishes. In the spirit of not abandoning his patient and since it is possible that the physician-patient relationship will be broken, the physician should be prepared to offer Edward the names of other clinicians with whom he can find therapeutic support and access medical treatments.

\subsection{Wrap-up}

In summary, people and their communities are complex. Problems with our cognitive and emotional abilities have profound effects. Understanding and defining human cognition and emotions and their interconnections continues to evolve in psychiatry, psychology, neurology, and neuroscience. Moreover, recent research and clinical advances in neurology and neuroscience have led to the emergence of neuroethics, the newest field within bioethics and one focused on the human brain and nervous system. In a sense, science and what is traditionally known as the medical complex have - rightly or wrongly - not yet assumed in relation to mental health and addictions the authoritative position they have in physical medicine and acute care settings.

Foundational ethical commitments and values remain relevant: for instance, the person's own wisdom and perspective, the community's obligations to all its members, the duties and limits of the state's intervention in individual and familial lives, a holistic view of factors contributing to individual and group well-being, and the immense, lasting harms of discrimination and stigma. Therefore, ethical understanding, engagement, and assistance for people's mental health and addiction problems, requires in-depth and broad analyses, multi-faceted and integrated responses, "the long view" and abiding commitment, nonreplication of past power imbalances and moralization, and a defensible role or place for law and legislation.

\section{References}

Acosta, F, Bosch, E, Sarmiento, G, Juanes, N, Caballero-Hidalgo, A \& Mayans, T. (2009). Evaluation of Noncompliance in Schizophrenia Patients Using Electronic Monitoring (MEMS) and its Relationship to Sociodemographic, Clinical and Psychopathological Variables. Schizophrenia Research, Vol. 107, Nos. 2-3 (February 2009), pp. 213-7, ISSN 0920-9964.

Amiel, J, Mangurian, C, Ganguli, R \& Newcomer, J. (2008). Addressing Cardiometabolic Risk During Treatment with Antipsychotic Medications. Current Opinion in Psychiatry, Vol. 21, No. 6 (November 2008), pp. 613-8, ISSN 0951-7367.

Andresen, M. (2006). Governments' Conflict of Interest in Treating Problem Gamblers. CMAJ, Vol. 175, No. 10 (November 2006), pp. 1191, ISSN 1488-2329. Aristotle. (2009). Nicomachean Ethics, World Classics Library, ISBN 019283407X, Des Moines

Austin, W. (2001). Relational Ethics in Forensic Psychiatric Settings. Journal of Psychosocial Nursing E Mental Health Services, Vol. 39, No. 9 (September 2001), pp. 12-7, ISSN 0279-3695. 
Banzato, C. (2004). Classification in Psychiatry: the move towards ICD-11 and DSM-V. Current Opinion in Psychiatry, Vol. 17, No. 6 (November 2004), pp. 497-501, ISSN 0951-7367.

Baum, F, Newman, L, Biedrzycki, K \& Patterson, J. (2010). Can a Regional Government's Social Inclusion Initiative Contribute to the Quest for Health Equity? Health Promotion International, Vol. 25, No. 4 (December 2010), pp. 474-82, ISSN 0957-4824.

Bissella, P, May, C \& Noyce, P. (2004). From Compliance to Concordance: barriers to accomplishing a re-framed model of health care interactions. Social Science $\mathcal{E}$ Medicine, Vol. 58, No. 4 (February 2004), pp. 851-62, ISSN 0277-9536.

Bogdanoski, T. (2009). Psychiatric Advance Directives: the new frontier in mental health law reform in Australia? Journal of Law E Medicine, Vol. 16, No. 5 (May 2009), pp. 891904, ISSN 1320-159X.

Burns, T \& Dawson, J. (2009). Community Treatment Orders: how ethical without experimental evidence? Psychological Medicine, Vol. 39, No. 10 (October 2009), pp. 1583-6, ISSN 0033-2917.

Canadian Mental Health Association. (2007). Poverty and Mental Illness. Retrieved from www.ontario.cmha.ca/backgrounders.asp?cID $=25341$.

Carter, S. (1996). Integrity. HarperPerennial, ISBN 9780060928070, New York.

Cleveland, M, Feinberg, M \& Greenberg, M. (2010). Protective Families in High- and LowRisk Environments: implications for adolescent substance use. Journal of Youth $\mathcal{E}$ Adolescence, Vol. 39, No. 2 (February 2010), pp. 114-26, ISSN 0047-2891.

Collier, R. (2010). DSM Revision Surrounded by Controversy. CMAJ, Vol. 182, No. 1 (January 2010), pp. 16-7, ISSN 1488-2329.

Corvette, B. (2000). Therapeutic Jurisprudence. Sociological Practice, Vol. 2, No. 2 (June 2000), pp. 127-32, ISSN 1522-3442.

Dickie, I. (2008). Ethical Dilemmas, Forensic Psychology, and Therapeutic Jurisprudence. Thomas Jefferson Law Review, Vol. 30, No. 2 (Spring 2008), pp. 455-61, ISSN 10905278.

Elisha, D, Castle, D \& Hocking, B. (2006). Reducing Social Isolation in People with Mental Illness: the role of the psychiatrist. Australasian Psychiatry, Vol. 14, No. 3 (September 2006), pp. 281-4, ISSN 1039-8562.

Finney, J \& Moos, R. (2006). Matching Clients' Treatment Goals with Treatment Oriented Towards Abstinence, Moderation or Harm Reduction. Addiction, Vol. 101, No. 11 (November 2006), pp. 1540-2, ISSN 0968-7610.

Flanagan, E, Miller, R \& Davidson, L. (2009). “Unfortunately, We Treat the Chart:" sources of stigma in mental health settings. Psychiatric Quarterly, Vol. 80, No. 1 (March 2009), pp. 55-64, ISSN 1573-6709.

Foucault, M. (1988). Madness and Civilization: a history of insanity in the age of reason. Random House, ISBN 067972110X, New York. Frank, A. (2004). Ethics as Process and Practice. Internal Medicine Journal, Vol. 34, No. 6 (June

Futterman, R, Lorente, M \& Silverman, S. (2004). Integrating Harm Reduction and Abstinence-Based Substance Abuse Treatment in the Public Sector. Substance Abuse, Vol. 25, No. 1 (March 2004), pp. 3-7, ISSN 0889-7077.

Gagne, C, White, W \& Anthony, W. (2007). Recovery: a common vision for the fields of mental health and addictions. Psychiatric Rehabilitation Journal, Vol. 31, No. 1 (Summer 2007), pp. 32-7, ISSN 1095-158X. 
Gouthro, T. (2009). Recognizing and Addressing the Stigma Associated with Mental Health Nursing: a critical perspective. Issues in Mental Health Nursing, Vol. 30, No. 11 (November 2009), pp. 669-76, ISSN 1061-2840.

Halter, M. (2008). Perceived Characteristics of Psychiatric Nurses: stigma by association. Archives of Psychiatric Nursing, Vol. 22, No. 1 (February 2008), pp. 20-6, ISSN 08839417.

Helzer, J, Bucholz, K \& Gossop, M. (2007). A Dimensional Option for the Diagnosis of Substance Dependence in DSM-V. International Journal of Methods in Psychiatric Research, Vol.16, No. S1 (June 2007), pp. S24-33, ISSN 1557-0657.

Hilfiker, D. (1992). The Case. Clint Wooder. Second Opinion, vol. 18, no. 2 (October 1992), pp. 42-53, ISSN 0890-1570.

Hofman, N, Strenski, T, Marshall, P \& Heimer, R. (2003). Maintaining Respectability and Responsibility: gendered labor patterns among women injection drug users. Health Care for Women International, Vol. 24, No. 9 (November 2003), pp. 794-807, ISSN 0739-9332.

Holland, M. (1998). Touching the Weights: moral perception and attention. International Philosophical Quarterly, Vol. 38, No. 3 (September 1998), pp. 299-312, ISSN 00190365.

Hudson, C. (2005). Socioeconomic Status and Mental Illness: tests of the social causation and selection hypotheses. American Journal of Orthopsychiatry, Vol. 75, No. 1, (January 2005), pp. 3-18, ISSN 1939-0025.

Hunt, A, da Silva, A, Lurie, S \& Goldbloom, D. (2007). Community Treatment Orders in Toronto: the emerging data. Canadian Journal of Psychiatry, Vol. 52, No. 10 (October 2007), pp. 647-56, ISSN 0706-7437.

Hwang, S. (2001) Homelessness and Health. CMAJ, Vol. 164, No. 2, (January 2001), pp. 22933, ISSN 1488-2329.

Ivanova, M \& Israel, A. (2006). Family Stability as a Protective Factor Against Psychopathology for Urban Children Receiving Psychological Services. Journal of Clinical Child E Adolescent Psychology, Vol. 35, No. 4 (December 2006), pp. 564-70, ISSN 1537-4416.

Johnson, C. (2004). The State of the Tobacco Settlement: are settlement funds being used to finance state government budget deficits? A research note. Public Budgeting $\mathcal{E}$ Finance, Vol. 24, No. 1 (March 2004), pp. 113-25, ISSN 0275-1100.

Kingdon, D \& Nicholl, J. (2006). Mental Health Research Continues to be Underfunded. BMJ, Vol. 332, No. 7556 (June 2006), pp. 1510, ISSN 0959-8138.

Knesper, D. (2007). My Favorite Tips for Engaging the Difficult Patient on ConsultationLiaison Psychiatry Services. Psychiatric Clinics of North America, Vol. 30, No. 2 (June

Korol, S. (2008). Familial and Social Support as Protective Factors Against the Development of Dissociative Identity Disorder. Journal of Trauma \& Dissociation, Vol. 9, No. 2, pp. 249-67, ISSN 1529-9732.

Kraemer, H. (2007). DSM Categories and Dimensions in Clinical and Research Contexts. International Journal of Methods in Psychiatric Research, Vol.16, No. S1 (June 2007), pp. S8-S15, ISSN 1557-0657.

Lauder, W, Kroll, T \& Jones, M. (2007). Social Determinants of Mental Health: the missing dimensions of mental health nursing? Journal of Psychiatric $\mathcal{E}$ Mental Health Nursing, Vol. 14, No. 7 (October 2007), pp. 661-9, ISSN 1351-0126. 
Lauro, L, Bass, A, Goldsmith, L, Kaplan, J, Katz, G \& Schaye. S. (2003). Psychoanalytic Supervision of the Difficult Patient. Psychoanalytic Quarterly, Vol. 72, No. 2 (April 2003), pp. 403-38, ISSN 0033-2828.

Liggins, J \& Hatcher, S. (2005). Stigma toward the Mentally Ill in the General Hospital: a qualitative study. General Hospital Psychiatry, Vol. 27, No. 5 (September 2005), pp. 359-64, ISSN 0163-8343.

Link, B \& Phelan J. (2001). Conceptualizing Stigma. Annual Review of Sociology, Vol. 27, No. 1 (2001), pp. 363-85, ISSN 0360-0572.

Livingstone, C \& Adams, P. (2011). Harm Promotion: observations on the symbiosis between government and private industries in Australasia for the development of highly accessible gambling markets. Addiction, Vol. 106, No. 1 (January 2011), pp. 38, ISSN 1074-3529.

Lowe, T \& Lubos, E. (2008). Effectiveness of Weight Management Interventions for People with Serious Mental Illness Who Receive Treatment with Atypical Antipsychotic Medications. A literature review. Journal of Psychiatric \& Mental Health Nursing, Vol. 15, No. 10 (December 2008), pp. 857-63, ISSN 1351-0126.

MacIntyre, A. (2007). After Virtue: a study in moral theory, third edition, University of Notre Dame Press, ISBN 9780268035044, Notre Dame.

Meltzer, H. (2008) State-of-Science Review: SR-B6 The Mental Ill-Health of Homeless People for Mental Capital and Wellbeing: Making the most of ourselves in the 21st century. Retrieved from www.bis.gov.uk/assets/bispartners/foresight/docs/mentalcapital/sr-b6_mcw.pdf.

Miller, W. (2008). The Ethics of Harm Reduction, In The Book of Ethics: expert guidance for professionals who treat addiction, Geppert, C \& Roberts, L, pp. 41-54, Hazelden, ISBN 9781592854929, Center City (MN).

Miller, P, Linteris, N \& Forzisi, L. (2008). Is Groin Injecting an Ethical Boundary for Harm Reduction? International Journal of Drug Policy, Vol. 19, No. 6 (December 2008), pp. 486-91, ISSN 0955-3959.

Moore, D. (2007). Translating Justice and Therapy: the drug treatment court networks. British Journal of Criminology, Vol. 47, No. 1 (January 2007), pp. 42-60, ISSN 00070955.

Morgan, C, Kirkbride, J, Hutchinson, G, Craig, T, Morgan, K, Dazzan, P, Boydell, J, Doody, G, Jones, P, Murray, R, Leff, J \& Fearon, P. (2008). Cumulative Social Disadvantage, Ethnicity and First-Episode Psychosis: a case-control study. Psychological Medicine,

Morgan, C, Burns, T, Fitzpatrick, R, Pinfold, V \& Priebe, S. (2007). Social Exclusion and Mental Health: conceptual and methodological review. British Journal of Psychiatry, Vol. 191, No. 6 (December 2007), pp. 477-83, ISSN 0007-1250.

Morse, S. (2008). The Ethics of Forensic Practice: reclaiming the wasteland. Journal of the American Academy of Psychiatry \& the Law, Vol. 36, No. 2 (June 2008), pp. 206-17, ISSN 1093-6793.

Muench, J \& Hamer, A. (2010). Adverse Effects of Antipsychotic Medications. American Family Physician, Vol. 81, No. 5 (March 2010), pp. 617-22, ISSN 0002-838X.

National Coalition for the Homeless. (2009) Mental Illness and Homelessness, (July 2009), Retrieved from www.nationalhomeless.org/factsheets/Mental_Illness.pdf.

National Institutes of Health. (2010). Summary of the FY 2011 President's Budget. Retrieved from 
http:/ / officeofbudget.od.nih.gov/pdfs/FY11/Summary\%20of\%20the \%20FY\%2020 11\%20Presidents\%20Budget.pdf.

Neale, J. (2008). Homelessness, Drug Use and Hepatitis C: a complex problem explored within the context of social exclusion. International Journal of Drug Policy, Vol. 19, No. 6 (December 2008), pp. 429-35, ISSN 0955-3959.

Nolan, J. (2003). Redefining Criminal Courts: problem solving and the meaning of justice. American Criminal Law Review, Vol. 40, No. 4 (Fall 2003), pp. 1541-65, ISSN 01640364 .

Nussbaum, M. (1985). Finely Aware and Richly Responsible: moral attention and the moral task of literature. Journal of Philosophy, Vol. 82, No. 10 (October 1985), pp. 516-29, ISSN 0022-362X.

Onken, S, Craig, C, Ridgway, P, Ralph, R \& Cook, J. (2007). An Analysis of the Definitions and Elements of Recovery: a review of the literature Psychiatric Rehabilitation Journal, Vol. 3, No. 1 (Summer 2007), pp. 9-22, ISSN 1095-158X.

Parker Jr., F \& Burke, L. (2005). Employers, Ethics, and Managed Care. Employee Benefit Plan Review, Vol. 59, No. 9 (February 2005), pp. 7-11, ISSN 0013-6808.

Piko, B \& Kovacs, E. (2010). Do Parents and School Matter? Protective factors for adolescent substance use. Addictive Behaviors, Vol. 35, No. 1 (January 2010), pp. 53-6, ISSN 0306-4603.

Pincus, H \& McQueen, L. (2002). The Limits of an Evidence-Based Classification of Mental Disorders, In Descriptions and Prescriptions: values, mental disorders, and the DSMs, Sadler, J (ed.), pp. 9-24, Johns Hopkins University Press, ISBN 0801868408, Baltimore.

Pouncey, C \& Lukens, J. (2010). Madness versus Badness: the ethical tension between the recovery movement and forensic psychiatry. Theoretical Medicine \& Bioethics, Vol. 31, No. 1 (February 2010), pp. 93-105, ISSN 1386-7415.

Proulx, M, Leduc, N, Vandelac, L, Gregoire, J \& Collin, J. (2007) Social Context, the Struggle with Uncertainty, and Subjective Risk as Meaning-Rich Constructs for Explaining HBP Noncompliance. Patient Education \& Counseling, Vol. 68, No. 1 (September 2007), pp. 98-106, ISSN 0738-3991.

Radcliffe, P \& Stevens, A. (2008). Are Drug Treatment Services Only for 'Thieving Junkie Scumbags'? Drug users and the management of stigmatized identities. Social Science E Medicine, Vol. 67, No. 7 (October 2008), pp. 1065-73, ISSN 0277-9536.

Radden, J \& Sadler, J. (2010). The Virtuous Psychiatrist. Oxford University Press, ISBN 9780195389371, Oxford.

Rose, D, Thornicroft, G, Pinfold, V \& Kassam, A. (2007). 250 Labels Used to Stigmatise People with Mental Illness. BMC Health Services Research, Vol. 7, No. 97 (June 2007), pp. 1-7, ISSN 1472-6963.

Ross, C \& Goldner, E. (2009). Stigma, Negative Attitudes and Discrimination Towards Mental Illness within the Nursing Profession: a review of the literature. Journal of Psychiatric \& Mental Health Nursing, Vol. 16, No. 6 (August 2009), pp. 558-67, ISSN 1351-0126.

Russell, B. (2008). An Integrative and Practical Approach to Ethics in Everyday Healthcare in Risk Management in Canadian Health Care, Dykeman, M \& Dewhirst, K (eds.), pp. 9-13, Lexis-Nexis Canada, ISBN 978433443988, Toronto.

Rx\&D. (2010). Code of Ethical Practices. Retrieved from 
https://www.canadapharma.org/en/commitment/healthcare/pdfs/2010\%20$\% 20$ Code $\% 20$ of $\% 20$ Ethical $\% 20$ Practices_en.pdf.

Schmidt, N, Kotov, R \& Joiner Jr., T. (2004). Taxometrics: toward a new diagnostic scheme for psychopathology. American Psychological Association, ISBN 1591471427, Washington DC.

Schulze, B. (2007). Stigma and Mental Health Professionals: a review of the evidence on an intricate relationship. International Review of Psychiatry, Vol. 19, No. 2 (January 2007), pp. 137-55, ISSN 0954-0261.

[Senate] Standing Committee on Social Affairs, Science and Technology. (2006). Out of the Shadows at Last. Retrieved from www.parl.gc.ca/39/1/parlbus/commbus/senate/com-e/soci-e/repe/pdf/rep02may06part1-e.pdf.

Shaffer, D, Hartman, J \& Listwan, S. (2009). Drug Abusing Women in the Community: The impact of drug court involvement on recidivism. Journal of Drug Issues, Vol. 39, No. 4, (Fall 2009), pp. 803-28, ISSN 0022-0426.

Skorpen, A, Anderssen, N, Oeye, C \& Bjelland, A. (2008). The Smoking Room as Psychiatric Patients' Sanctuary: a place for resistance. Journal of Psychiatric and Mental Health Nursing, Vol. 15, No. 9 (November 2008), pp. 728-36, ISSN 1365-2850.

Smith, T \& Hirdes, J. (2009). Predicting Social Isolation Among Geriatric Psychiatry Patients. International Psychogeriatrics, Vol. 21, No. 1 (February 2009), pp. 50-9, ISSN 10416102.

Sokol, D. (2007). Ethicist on the Ward Round. BMJ, Vol. 335, No. 7621 (September 2007), pp. 670, ISSN 0959-8138.

Srebnik, D \& Russo, J. (2008). Use of Psychiatric Advance Directives During Psychiatric Crisis Events. Administration \& Policy in Mental Health, Vol. 35, No. 4 (July 2008), pp. 272-82, ISSN 0894-587X.

Srebnik, D, Rutherford, L, Peto, T, Russo, J, Zick, E, Jaffe, C \& Holtzheimer, P. (2005). The Content and Clinical Utility of Psychiatric Advance Directives. Psychiatric Services, Vol. 56, No. 5 (May 2005), pp. 592-8, ISSN 1075-2730.

Stewart, D \& DeMarco J. (2010) Rational Noncompliance with Prescribed Medical Treatment. Kennedy Institute of Ethics Journal, Vol. 20, No. 3 (September 2010), pp.

Stuhlmiller, C. (2005). Promoting Student Interest in Mental Health Nursing, Journal of the American Psychiatric Nursing Association, Vol. 11, No. 6 (December 2005), pp. 355-8, ISSN 1078-3903.

Sutherby, K, Szmukler, G, Halpern, A, Alexander, M, Thornicroft, G, Johnson, C \& Wright, S. (1999). A Study of "Crisis Cards" in a Community Psychiatric Service. Acta Psychiatrica Scandinavica, Vol. 100, No. 1 (July 1999), pp. 56-61, ISSN 0001-690X.

Swanson, J, McCrary, S, Swartz, M, Elbogen, E \& Van Dorn, R. (2006). Superseding Psychiatric Advance Directives: ethical and legal considerations. Journal of the American Academy of Psychiatry \& the Law, Vol. 34, No. 3 (September 2006), pp. 38594, ISSN 1093-6793.

Szasz, T. (2009). Antipsychiatry: quackery squared. Syracuse University Press, ISBN 9780815609438, Syracuse.

Szasz, T. (1976). Schizophrenia: the sacred symbol of psychiatry. BasicBooks, ISBN 9780465072224, New York. 
Szasz, T. (1961). The Myth of Mental Illness: foundations of a theory of personal conduct. Harper \& Row, ISBN 0060141964, New York.

Tessman, L. (2005). Burdened Virtues: virtue ethics for liberatory struggles. Oxford University Press, ISBN 9780195179156, Oxford.

Walker, D \& Jackson J. (2011). The Effect of Legalized Gambling on State Government Revenue. Contemporary Economic Policy, Vol. 29, No. 1 (January 2011), pp. 101-14, ISSN 1465-7287.

Wilson, A \& Beresford, P. (2002) Madness, Distress and Postmodernity, In Embodying Disability Theory, Corker, M \& Shakespeare, T (eds.), pp. 143-58, Continuum, ISBN 0826450555, London (U.K.).

Wilson, H \& Skodol, A. (1994). Special Report: DSM-IV: overview and examination of major changes. Archives of Psychiatric Nursing, Vol. 8, No. 6 (December 1994), pp. 340-7, ISSN 0883-9417.

Wilton, R. (2004). Putting Policy into Practice? Poverty and people with serious mental illness. Social Science \& Medicine, Vol. 58, No. 1 (January 2004), pp. 25-39, ISSN 02779536.

Winkler, E. (2005). The Ethics of Policy Writing: how should hospitals deal with moral disagreement about controversial medical practices? Journal of Medical Ethics, Vol. 31, No. 10, (October 2005), pp. 559-66, ISSN 0306-6800.

World Health Organization. (2004). The World Medicines Situation. Retrieved from http://apps.who.int/medicinedocs/pdf/s6160e/s6160e.pdf.

World Health Organization. (2003). Social Determinants of Health: the solid facts, second edition. Wilkinson, R \& Marmot, M. (eds.). Retrieved from www.euro.who.int/ data/assets/pdf_file/0005/98438/e81384.pdf.

Zaner, R. (2004). Ethics and the Clinical Encounter. First Academic Renewal Press, ISBN 0788099396, Lima (OH). 


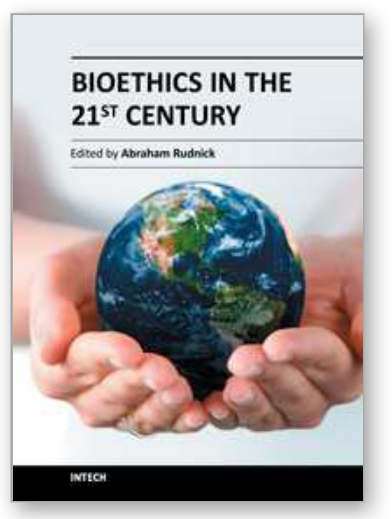

\author{
Bioethics in the 21st Century \\ Edited by Prof. Abraham Rudnick
}

ISBN 978-953-307-270-8

Hard cover, 158 pages

Publisher InTech

Published online 25, November, 2011

Published in print edition November, 2011

Bioethics is primarily an applied ethics of health related issues. It is considered an important guide for health care and its discourses and practices. Health related technology, such as information technology, is changing rapidly. Bioethics should arguably address such change as well as continue to address more established areas of health care and emerging areas of social concern such as climate change and its relation to health. This book illustrates the range of bioethics in the 21 st century. The book is intentionally not comprehensive but rather illustrative of established, emerging and speculative bioethics, such as ethics of mental health care, ethics of nano-technology in health care, and ethics of cryogenics, respectively. Hopefully the book will motivate readers to reflect on health care as a work in progress that requires continuous ethical deliberation and guidance.

\title{
How to reference
}

In order to correctly reference this scholarly work, feel free to copy and paste the following:

Barbara J. Russell (2011). Ethics Related to Mental Illnesses and Addictions, Bioethics in the 21st Century, Prof. Abraham Rudnick (Ed.), ISBN: 978-953-307-270-8, InTech, Available from: http://www.intechopen.com/books/bioethics-in-the-21st-century/ethics-related-to-mental-illnesses-andaddictions

\section{INTECH}

open science | open minds

\author{
InTech Europe \\ University Campus STeP Ri \\ Slavka Krautzeka 83/A \\ 51000 Rijeka, Croatia \\ Phone: +385 (51) 770447 \\ Fax: +385 (51) 686166 \\ www.intechopen.com
}

\author{
InTech China \\ Unit 405, Office Block, Hotel Equatorial Shanghai \\ No.65, Yan An Road (West), Shanghai, 200040, China \\ 中国上海市延安西路65号上海国际贵都大饭店办公楼 405 单元 \\ Phone: +86-21-62489820 \\ Fax: +86-21-62489821
}


(C) 2011 The Author(s). Licensee IntechOpen. This is an open access article distributed under the terms of the Creative Commons Attribution 3.0 License, which permits unrestricted use, distribution, and reproduction in any medium, provided the original work is properly cited. 